\title{
$C_{0} \mathbf{I} \cdot \mathbf{R}^{\circ} \mathbf{P} \cdot \mathrm{E}^{\prime} \mathrm{E}$
}

Centre Interuniversitaire sur le Risque, les Politiques Économiques et l'Emploi

Cahier de recherche/Working Paper 14-02

\section{Public Investment, Time to Build, and the Zero Lower Bound}

\author{
Hafedh Bouakez \\ Michel Guillard \\ Jordan Roulleau-Pasdeloup
}

Janvier/January 2014

Bouakez: Institute of Applied Economics and CIRPÉE, HEC Montréal, 3000 chemin de la Côte-Sainte-Catherine, Montréal, Québec, Canada H3T 2A7; Tel.: 1514 340-7003; Fax: 1514 340-6469

hafedh.bouakez@hec.ca

Guillard: EPEE, Université d'Evry Val d'Essonne, bd F. Mitterrand, 91025 Evry Cedex, France

michel.guillard@univ-evry.fr

Roulleau-Pasdeloup: CREST and Paris School of Economics, Centre d'Économie de la Sorbonne - 15 Boulevard Gabriel Peri, 92245 Malakoff Cedex. Tel.: +33141177792

jordan.roulleau-pasdeloup@ensae.fr

Financial support from SSHRC and FRQSC is gratefully acknowledged. We thank Matteo Cacciatore, Larry Christiano, Giancarlo Corsetti, Ferhat Mihoubi, and Federico Ravenna for helpful comments and discussions. 


\begin{abstract}
:
Public investment represents a non-negligible fraction of total public expenditures. Yet, theoretical studies of the effects of public spending when the economy is stuck in a liquidity trap invariably assume that government expenditures are entirely wasteful. In this paper, we consider a new-Keynesian economy in which a fraction of government spending increases the stock of public capital-which is an external input in the production technology-subject to a time-to-build constraint. In this environment, an increase in public spending has two conflicting effects on current and expected inflation: a positive effect due to higher aggregate demand and a negative effect reflecting future declines in real marginal cost. We solve the model analytically both in normal times and when the zero lower bound (ZLB) on nominal interest rates binds. We show that under relatively short time-to-build delays, the spending multiplier at the ZLB decreases with the fraction of public investment in a stimulus plan. Conversely, when several quarters are required to build new public capital, this relationship is reversed. In the limiting case where a fiscal stimulus is entirely allocated to investment in public infrastructure, the spending multiplier at the ZLB is 4 to 5 times larger than in normal times when the time to build is 12 quarters.
\end{abstract}

Keywords: Public spending, Public investment, Time to build, Multiplier, Zero lower bound

JEL Classification: E4, E52, E62, H54 
"In a depressed economy, with the government able to borrow at very low interest rates, we should be increasing public investment."

Paul Krugman, The New York Times, September 12, 2012

"We can create some room to invest in things that make America stronger, like rebuilding America's infrastructure."

Timothy F. Geithner, The New York Times, December 4, 2012

\section{Introduction}

One of the most widely debated questions since the onset of the latest global recession has been the effectiveness of public spending as a tool to stimulate the economy. This effectiveness is commonly judged by the size the spending multiplier, that is, the dollar change in aggregate output that results from a dollar increase in public expenditures. From an empirical standpoint, estimates of the spending multiplier range from roughly 0 to well above 1 , depending on the sample period and the identifying assumptions. ${ }^{1}$ Most theoretical models, on the other hand, yield a spending multiplier in the neighborhood of $1 .^{2}$ The main assumption underlying the latter prediction, one that is also implicit in the empirical literature, is that the economy is in "normal times".

Recent theoretical research by Eggertsson (2011), Woodford (2011) and Christiano et al. (2011), however, shows that during sharp recessions that drive nominal interest rates down to their lower bound of zero - rendering conventional monetary policy useless - an increase in public spending can be very effective in stimulating economic activity. In this situation, often referred to as a liquidity trap, the spending multiplier is 2 to 3 times larger than in normal times, under plausible parameter values. Intuitively, by raising aggregate demand, government spending does what monetary policy cannot do: generate inflation. Since the nominal interest rate is stuck at zero, the real interest rate falls, thus further boosting aggregate demand.

These earlier papers have in common the assumption that public spending is entirely wasteful and has no direct effect on the marginal productivity of private inputs. More specifically, they abstract from public investment despite the fact that it represents a non-negligible fraction of total public spending, averaging roughly 23 percent in the U.S. for example. More importantly,

\footnotetext{
${ }^{1}$ See, for example, Ramey \& Shapiro (1998), Ramey (2011), Fatás \& Mihov (2001), Blanchard \& Perotti (2002), Perotti (2005), Galí et al. (2007), Mountford \& Uhlig (2009), Barro \& Redlick (2011), Auerbach \& Gorodnichenko (2012) and Bouakez et al. (2013) among others.

${ }^{2}$ See Perotti (2008) and Hall (2009) for comprehensive surveys of the theoretical literature.
} 
Bachmann \& Sims (2012) show that, conditional on a positive government spending shock, the ratio of public investment to public consumption tends to rise more during recessions than during expansions. According to the 2009 American Recovery and Reinvestment Act, of the $\$ 550$ billion of planned public spending, roughly $\$ 159$ billion (that is, 28.9 percent) was set to go into infrastructure.

The popular argument in favor of public investment is that it allows to kill two birds with one stone: stimulate aggregate demand in the short run while fostering long-run growth with better infrastructure. While this may be true, the effectiveness of public investment as a fiscal stimulus nonetheless depends on the way in which it affects expected inflation. To the extent that public capital is productive, an increase in public investment will have two opposite effects on future real marginal costs: $(i)$ a negative (supply-side) effect reflecting the expected increase in the marginal productivity of private inputs, and (ii) a positive effect stemming from the increase in future aggregate demand due to the increase in households' expected wealth. Expected inflation, and thus the output effect of public investment, will depend on the relative importance of these two forces at different time horizons.

The purpose of this paper is to evaluate the size of the spending multiplier in a model with public capital, both in normal times and when the zero lower bound (ZLB) on nominal interest rates binds. We present an analytically tractable new-Keynesian model in which a fraction of government spending is in the form of public investment. The latter increases the stock of public capital, which is an external input in the production technology. In order to account for the implementation delays associated with the completion of investment projects, we assume that multiple periods are required to build new productive (public) capital. ${ }^{3}$ Monetary policy sets the nominal interest rate according to a Taylor-type rule subject to a non-negativity constraint. As in Woodford (2011), Eggertsson (2011), and Christiano et al. (2011), we assume that states of the world in which the ZLB binds are the result of a large negative shock to the discount rate, which increases agents' desire to save. ${ }^{4}$

We start by considering a simplified version of our model in which public investment becomes productive within the period (i.e., without implementation delay), and public capital fully depreciates after one period. Since this version of the model has no (endogenous) state variable, the spending multiplier can be easily characterized. We show that, in normal times, the spending multiplier increases linearly with the fraction of public investment in a stimulus plan, whereas the

\footnotetext{
${ }^{3}$ The assumption of time to build was first introduced by Kydland \& Prescott (1982) in the context of a real business cycle model.

${ }^{4}$ Alternatively, Mertens \& Ravn (2010) assume that the economy is plunged in a liquidity trap as a result of a sudden change in agents' beliefs that is not motivated by fundamentals.
} 
opposite result holds when the ZLB binds. Intuitively, when there is no accumulation of public capital, an increase in public spending has only contemporaneous effects on real marginal cost: a positive effect due to the direct increase in aggregate demand and a negative effect due to the externality associated with the productive component of the stimulus. The larger this component, the lower current and expected inflation. In normal times, this translates into a smaller response of the nominal and real interest rates and thus a larger output response. When the ZLB binds, on the other hand, this implies a larger response of the real interest rate. Quantitatively, when the fraction of public investment in a stimulus plan exceeds 35 percent, the spending multiplier exceeds 1 in normal times and is negative when the ZLB binds.

We then consider the more general case with time-to-build and an empirically plausible depreciation rate of public capital. We show that the relationship between the size of the spending multiplier and the fraction of investment spending in a stimulus plan crucially depends on the length of time to build. In normal times, the multiplier is an increasing (decreasing) function of the fraction of public investment when the time to build is relatively short (long). In all cases, however, the multiplier remains close to 1 , as is the case in a model with exclusively unproductive public spending. When the ZLB binds, the spending multiplier becomes a decreasing (increasing) function of the fraction of public investment when the implementation delay is relatively short (long). In the limiting case where a fiscal stimulus is entirely allocated to public investment in infrastructure, the spending multiplier at the ZLB is 4 to 5 times larger than in normal times when the time to build is 12 quarters.

The intuition for these results is the following. When more than one period is required for public capital to become productive, the increase in public investment raises the stock of capital in subsequent periods thus giving rise to the aforementioned supply- and demand-side effects on future real marginal costs. The demand-side effect tends to amplify the response of inflation at short horizons to an extent that depends positively on the share of public investment in the stimulus, whereas the supply-side effect tends to dampen the response of inflation at longer horizons, also to an extent that increases with the productive component of the stimulus. When the time to build is short, the supply-side effect quickly comes into play so that expected inflation is mainly driven by future declines in real marginal cost. In normal times, this leads to a smaller decline in the long-term ex ante real interest rate, and therefore to a larger consumption response, as the fraction of public investment becomes larger. As the implementation lag increases, the supplyside effect of productive public spending is further delayed and the dynamic response of inflation 
becomes increasingly driven by current and futures increases in aggregate demand. In response to the increase in public sending, inflation thus rises more sharply and more persistently the larger is the fraction of public investment. This in turn translates into a larger response of the long-termreal interest rate and thus a smaller response of consumption. When the ZLB binds, the nominal interest rate cannot adjust, so that the real interest rate moves in opposite direction to expected inflation. The effects described above are therefore reversed.

In addition to the literature cited above, this paper is closely related to those by Baxter \& King (1993), Linnemann \& Schabert (2006), and Leeper et al. (2010), who study the business-cycle implications of public investment in the context of general-equilibrium models. Baxter \& King (1993) and Leeper et al. (2010) consider a neoclassical framework, whereas Linnemann \& Schabert (2006) consider a model with nominal rigidities. Of all the three papers, only that by Leeper et al. (2010) allows for a time-to-build technology for the production of public capital. ${ }^{5}$ Unlike our paper, however, none of these earlier studies treats the case of a binding ZLB.

The rest of this paper is organized as follows. Section 2 describes the economy. Section 3 derives the spending multiplier in a simple version of the model without time to build and with full depreciation of the stock of public capital. Section 4 studies the spending multiplier in the more general case. Section 5 concludes.

\section{The Economy}

We consider a new-Keynesian economy with infinitely lived households, firms, a government, and a monetary authority. The key feature of the model is that a fraction of government spending is invested in public capital subject to a time-to-build requirement. The stock of public capital enters as an external input in the production of intermediate goods, which are used to produce an homogenous final good. The latter is used for consumption and investment purposes. Intermediategood producers are monopolistically competitive and set their prices à la Calvo, whereas finalgood producers are perfectly competitive. The monetary authority sets the nominal interest rate according to a Taylor-type rule subject to a non-negativity constraint.

\footnotetext{
${ }^{5}$ Baxter \& King (1993) assume that only one period is required to build new public capital, whereas Linnemann \& Schabert (2006) assume that public spending is productive only during the period in which it occurs, an assumption originally introduced by Barro (1990).
} 


\section{$2.1 \quad$ Households}

The economy is populated by a large number of identical households who have the following lifetime utility function: ${ }^{6}$

$$
E_{t} \sum_{s=0}^{\infty} d_{t+s} U\left(C_{t+s}, N_{t+s}\right),
$$

where $C_{t}$ is consumption, $N_{t}$ denotes hours worked, and $d_{t}$ is a time-varying discount factor defined by

$$
d_{t+s}=\left\{\begin{array}{cc}
\beta_{t+1} \beta_{t+2} \ldots \beta_{t+s} & s \geq 1 \\
1 & s=0
\end{array}\right.
$$

where $0<\beta_{t+s}<1$ is known in $t+s-1$ with certainty.

The representative household enters period $t$ with $\mathcal{B}_{t-1}$ units of one-period riskless nominal bonds. During the period, it receives a wage payment, $\mathcal{W}_{t} N_{t}$, and dividends, $\mathcal{D}_{t}$, from the monopolistically competitive firms. This income is used to pay a lump-sum tax, $\mathcal{T}_{t}$, to the government, to consumption, and to the purchase of new bonds. The household's budget constraint is therefore

$$
P_{t} C_{t}+\mathcal{T}_{t}+\frac{\mathcal{B}_{t}}{1+i_{t}} \leq \mathcal{W}_{t} N_{t}+\mathcal{D}_{t}+\mathcal{B}_{t-1}
$$

where $P_{t}$ is the price of the final good, $\mathcal{W}_{t}$ is nominal wage rate, and $\frac{1}{1+i_{t}}$ is the price of a nominal bond purchased at time $t, i_{t}$ being the nominal interest rate. The household maximizes (1) subject to $(2)$ and to no-Ponzi-game condition. The first order conditions for this problem are given by

$$
\begin{aligned}
W_{t} & =-\frac{U_{N}\left(C_{t}, N_{t}\right)}{U_{C}\left(C_{t}, N_{t}\right)}, \\
\frac{1}{1+i_{t}} & =\beta_{t+1} E_{t}\left(\frac{U_{C}\left(C_{t+1}, N_{t+1}\right)}{U_{C}\left(C_{t}, N_{t}\right)} \frac{P_{t}}{P_{t+1}}\right),
\end{aligned}
$$

where $W_{t}=\frac{\mathcal{W}_{t}}{P_{t}}$ is the real wage rate and $U_{X}\left(C_{t}, N_{t}\right)=\partial U\left(C_{t}, N_{t}\right) / \partial X_{t}$. Note that the conditionalexpectation operator, $E_{t}$, is not applied to $\beta_{t+1}$ because the latter is known in period $t$.

\section{$2.2 \quad$ Firms}

The final good is produced by perfectly competitive firms using the following constant-elasticityof-substitution technology:

$$
Y_{t}=\left[\int_{0}^{1} X_{t}(z)^{1-1 / \theta} d z\right]^{\frac{\theta}{\theta-1}}
$$

\footnotetext{
${ }^{6}$ The equilibrium dynamics of this economy are identical to those of an economy in which public spending affects preferences in an additively separable manner (as in Christiano et al. (2011)). Since the focus of this paper is not on the normative implications of fiscal policy, we simply assume that public spending does not enter the utility function.
} 
where $Y_{t}(z)$ is the quantity of intermediate good $z$ and $\theta \geq 1$ is the elasticity of substitution between intermediate goods. Denoting by $P_{t}(z)$ the price of intermediate good $z$, demand for $z$ is given by

$$
X_{t}(z)=\left(\frac{P_{t}(z)}{P_{t}}\right)^{-\theta} Y_{t}
$$

Firms in the intermediate-good sector are monopolistically competitive, each producing a differentiated good using labor as a direct input and public capital as an external input

$$
X_{t}(z)=F\left(N_{t}(z), K_{t}\right)=J\left(N_{t}(z)\right) H\left(K_{t}\right)
$$

where the function $J($.$) is such that J\left(U_{t} V_{t}\right)=J\left(U_{t}\right) J\left(V_{t}\right)$. Intermediate-good producers set their prices à la Calvo. That is, in each period, a given firm resets its price with probability $1-\phi$. Denoting by $P_{t}^{o}$ the optimal price chosen in period $t$, the firm's problem is

$$
\max _{P_{t}^{o}} E_{t} \sum_{s=0}^{\infty} \phi^{s} Q_{t, t+s}\left\{P_{t}^{o} X_{t, t+s}-(1-\tau) \mathcal{W}_{t+s} N_{t, t+s}\right\}
$$

subject to

$$
X_{t, t+s}=F\left(N_{t, t+s}, K_{t+s}\right)
$$

and

$$
X_{t, t+s}=\left(\frac{P_{t}^{o}}{P_{t+s}}\right)^{-\theta} Y_{t+s}
$$

where $Q_{t, t+s}=d_{t+s} U_{C}\left(C_{t+s}, N_{t+s}\right) / d_{t} U_{C}\left(C_{t}, N_{t}\right)$ is the stochastic discount factor; $X_{t, t+s}$ and $N_{t, t+s}$ are, respectively, the quantity of intermediate good produced and labor demand in period $t+s$ if the price set at time $t$ is still in effect; and $\tau=1 / \theta$ is a subsidy that corrects the steady-state distortion stemming from monopolistic competition.

The first order condition for this program is given by

$$
E_{t} \sum_{s=0}^{\infty} \phi^{s} Q_{t, t+s} X_{t, t+s}\left[P_{t}^{o}-\mu M C_{t, t+s}\right]=0,
$$

where $M C_{t, t+s}=\frac{(1-\tau) \mathcal{W}_{t+s}}{F_{N}\left(N_{t, t+s}, K_{t+s}\right)}$ is the marginal cost of producing an additional unit of output in period $t+s$ if the price set at time $t$ is still in effect, and $\mu=\theta /(\theta-1)$ is the desired steady-state markup over marginal cost.

Given the price setting mechanism just described, the price of the final good evolves according to

$$
P_{t}^{1-\theta}=(1-\phi)\left(P_{t}^{o}\right)^{1-\theta}+\phi P_{t-1}^{1-\theta}
$$




\subsection{Fiscal and monetary authorities}

The government levies lump-sum taxes to finance its expenditures and the subsidy given to firms in the intermediate-good sector. Its budget constraint is given by

$$
P_{t} G_{t}+(1-\tau) \mathcal{W}_{t} N_{t}=\mathcal{T}_{t}
$$

where $G_{t}$ is government spending, which composed of two parts, public consumption and public investment

$$
G_{t}=G_{t}^{c}+G_{t}^{i}
$$

Public investment increases the stock of public capital according to the following accumulation equation:

$$
K_{t}=(1-\delta) K_{t-1}+G_{t-T}^{i}
$$

where $T \geq 0$. This specification allows for the possibility that several periods may be required to build new productive capital, i.e., time to build (see Kydland \& Prescott (1982)). This feature reflects the implementation delays typically associated with the different stages of public investment projects (planning, bidding, contracting, construction, etc.). ${ }^{7}$

In normal times, public spending is determined by the following process:

$$
G_{t}=(1-\rho) G+\rho G_{t-1}+\epsilon_{t}
$$

where $0 \leq \rho<1, G$ is the steady-state level of public spending, and $\epsilon_{t}$ is a zero-mean serially uncorrelated disturbance. The dynamics of public spending when the economy is plunged in a liquidity trap will be described in Section 3.2. Moreover, we assume that public investment is determined by the following policy rule:

$$
G_{t}^{i}=G^{i}+\alpha\left(G_{t}-G\right)
$$

where $0 \leq \alpha \leq 1$ and $G^{i}$ is the steady-state level of public investment. The policy parameter $\alpha$ measures the fraction of public investment in a spending-based stimulus plan. Note that this fraction need not be equal to the steady-state share of public investment in total public expenditures.

The monetary policy is described by a simple Taylor-type rule subject to a non-negativity

\footnotetext{
${ }^{7}$ In general, the outlays of an investment project occur gradually over time after the budget has been authorized. To keep the model analytically tractable, however, we abstract from this issue and simply assume that investment expenditures are outlaid in full at the time of the authorization.
} 
constraint on the nominal interest rate

$$
i_{t}=\max \left(0 ; \ln \beta^{-1}+\phi_{\pi} \ln \Pi_{t}\right),
$$

where $\Pi_{t}=P_{t} / P_{t-1}$ is the gross inflation rate between $t-1$ and $t$.

\subsection{Market clearing and equilibrium}

Market clearing for each intermediate good $z$ requires that

$$
F\left(N_{t}(z), K_{t}\right)=J\left(N_{t}(z)\right) H\left(K_{t}\right)=\left(\frac{P_{t}(z)}{P_{t}}\right)^{-\theta} Y_{t}
$$

which implies

$$
N_{t}(z)=J^{-1}\left[\frac{Y_{t}}{H\left(K_{t}\right)}\left(\frac{P_{t}(z)}{P_{t}}\right)^{-\theta}\right] .
$$

Aggregating across all intermediate-good producers and imposing labor market equilibrium, we obtain

$$
N_{t}=J^{-1}\left(\frac{Y_{t}}{H\left(K_{t}\right)}\right) \int J^{-1}\left[\left(\frac{P_{t}(z)}{P_{t}}\right)^{-\theta}\right] d z .
$$

This yields

$$
Y_{t}=\frac{F\left(N_{t}, K_{t}\right)}{\Delta_{t}}
$$

where $\Delta_{t}=J\left(\int J^{-1}\left[\left(\frac{P_{t}(z)}{P_{t}}\right)^{-\theta}\right] d z\right)$ is a measure of dispersion of relative prices, which will be equal to zero up to a first order approximation of the model around a symmetric steady state.

Since households are identical, the net supply of bonds must be zero in equilibrium $\left(\mathcal{B}_{t}=0\right)$. Finally, the resource constraint is

$$
Y_{t}=C_{t}+G_{t}
$$

A competitive intertemporal equilibrium for this economy is a sequence of prices $\left\{P_{t}(z), P_{t}, W_{t}, i_{t}\right\}_{t=0}^{\infty}$ and quantities $\left\{X_{t}(z), N_{t}(z), N_{t}, Y_{t}, C_{t}, K_{t}, G_{t-T}^{i}\right\}_{t=0}^{\infty}$ such that, for a given sequence of exogenous variables $\left\{\beta_{t}, G_{t}\right\}_{t=0}^{\infty}$, households and firms solve their respective optimization problems, the accumulation equation of public capital holds, the spending and monetary rules hold, and all markets clear. The model equations are listed in Appendix A.1.

\subsection{Log-linearized model}

The model is solved by log-linearizing the equilibrium conditions around a deterministic zeroinflation steady state. In what follows, variables without a time subscript denote steady-state values 
and variables in lowercase denote percentage deviations from steady state $\left(z_{t}=\left(Z_{t}-Z\right) / Z\right)$, except for $g_{t}=\left(G_{t}-G\right) / Y$ and $g_{t}^{i}=\left(G_{t}^{i}-G^{i}\right) / Y$. Defining $r_{\beta, t}=-\ln \left(\beta_{t}\right), \bar{g}=G / Y$ and $\bar{\alpha}=G^{i} / G$, the log-linearized model is given by (see Appendix A.3 for details)

$$
\begin{aligned}
c_{t} & =E_{t} c_{t+1}-\Phi_{r}\left(i_{t}-E_{t} \pi_{t+1}-i_{\beta, t}\right)+\Phi_{g}\left(g_{t}-E_{t} g_{t+1}\right)-\Phi_{k}\left(k_{t}-E_{t} k_{t+1}\right), \\
\pi_{t} & =\beta E_{t} \pi_{t+1}+\kappa\left(\Theta_{c} c_{t}+\Theta_{g} g_{t}-\Theta_{k} k_{t}\right) \\
k_{t} & =(1-\delta) k_{t-1}+\tilde{\delta} g_{t-T} \\
i_{t} & =\max \left(0 ; r_{\beta, t}+\phi_{\pi} \pi_{t}\right)
\end{aligned}
$$

where

$$
\begin{aligned}
\Phi_{r} & =\frac{-\frac{U_{C}}{U_{C C} C}}{1+(1-\bar{g}) \frac{U_{C N} N}{U_{C C} C} \frac{F}{F_{N} N}} \quad \Phi_{g}=\frac{F}{F_{N} N} \frac{U_{C N} N}{U_{C}} \Phi_{r}, \quad \Phi_{k}=\frac{F_{K} K}{F} \Phi_{g}, \\
\Theta_{c} & =\left(\frac{U_{C N} C}{U_{N}}-\frac{U_{C C} C}{U_{C}}\right)+(1-\bar{g}) \Theta_{g}, \\
\Theta_{g} & =\left(\frac{U_{N N} N}{U_{N}}-\frac{U_{C N} N}{U_{C}}-\frac{F_{N N} N}{F_{N}}\right) \frac{F}{F_{N} N}, \quad \Theta_{k}=\frac{F_{N K} K}{F_{N}}+\frac{F_{K} K}{F} \Theta_{g},
\end{aligned}
$$

and

$$
\begin{aligned}
\kappa & =\frac{(1-\phi)(1-\beta \phi)}{\phi} \frac{-\frac{F_{N N} N}{F_{N}}}{-\frac{F_{N N} N}{F_{N}}+\theta\left(1+\frac{F_{N N} N}{F_{N}}\right)}>0, \\
\tilde{\delta} & =\frac{\alpha \delta}{\bar{\alpha} \bar{g}} \geq 0 .
\end{aligned}
$$

Model (17)-(20) nests the special case considered by Christiano et al. (2011), Eggertsson (2011) and Woodford (2011), where public spending plays no productive role. This case can be recovered either by assuming that $F_{K}=0$ (which implies that $\Phi_{k}=\Theta_{k}=0$ ) or by setting $\alpha=0$ (which implies that $\tilde{\delta}=0)$. In the former case, public spending has a zero marginal productivity and thus does not effect the marginal productivity of private inputs. In the latter, the fraction of total public spending devoted to investment is nil, implying that the stock of public capital remains constant at its steady-state level.

\section{A Special Case}

Consider the case where $(i)$ public investment increases public capital contemporaneously, i.e., with no time-to-build $(T=0)$, (ii) public capital depreciates fully at the end of each period $(\delta=1)$, and (iii) the utility function is additively separable in consumption and leisure $\left(U_{C N}=0\right)$. The first two 
conditions imply that the model has no (endogenous) state variable. The third condition implies that $\Phi_{g}=\Phi_{k}=0$ and that $\Phi_{r}, \Theta_{c}, \Theta_{g}$, and $\Theta_{k}$ are all positive. In this case, model (17)-(20) collapses to

$$
\begin{aligned}
c_{t} & =E_{t} c_{t+1}-\Phi_{r}\left(i_{t}-E_{t} \pi_{t+1}-i_{\beta, t}\right), \\
\pi_{t} & =\beta E_{t} \pi_{t+1}+\kappa\left(\Theta_{c} c_{t}+\left(\Theta_{g}-\tilde{\delta} \Theta_{k}\right) g_{t}\right), \\
i_{t} & =\max \left(0 ; r_{\beta}+\phi_{\pi} \pi_{t}\right) .
\end{aligned}
$$

This version of the model will allow us to obtain a tractable analytical characterization of the effects of government spending in normal times and when the ZLB binds.

\subsection{The spending multiplier in normal times}

In normal times, the nominal interest rate is strictly positive and is determined by

$$
i_{t}=r_{\beta}+\phi_{\pi} \pi_{t}
$$

For simplicity, we also assume that the discount factor is constant (i.e., $r_{\beta, t}=r_{\beta}$ ). Under these assumptions, system (21)-(23) becomes

$$
\begin{aligned}
c_{t} & =E_{t} c_{t+1}-\Phi_{r}\left(\phi_{\pi} \pi_{t}-E_{t} \pi_{t+1}\right), \\
\pi_{t} & =\beta E_{t} \pi_{t+1}+\kappa\left(\Theta_{c} c_{t}+\left(\Theta_{g}-\tilde{\delta} \Theta_{k}\right) g_{t}\right) .
\end{aligned}
$$

Under the assumption that $\phi_{\pi}>1$, and given the process (13), the unique linear rational expectation solution of the system above is given by

$$
\begin{aligned}
c_{t} & =\vartheta_{g} g_{t}, \\
\pi_{t} & =\zeta_{g} g_{t},
\end{aligned}
$$

where

$$
\begin{aligned}
\vartheta_{g} & =-\frac{\kappa\left(\phi_{\pi}-\rho\right)\left(\Theta_{g}-\tilde{\delta} \Theta_{k}\right) \Phi_{r}}{(1-\rho)(1-\beta \rho)+\kappa\left(\phi_{\pi}-\rho\right) \Phi_{r} \Theta_{c}} \\
\zeta_{g} & =\frac{\kappa(1-\rho)\left(\Theta_{g}-\tilde{\delta} \Theta_{k}\right)}{(1-\rho)(1-\beta \rho)+\kappa\left(\phi_{\pi}-\rho\right) \Phi_{r} \Theta_{c}} .
\end{aligned}
$$


Using the log-linearized resource constraint, $y_{t}=(1-\bar{g}) c_{t}+g_{t}$, we obtain the following expression for the spending multiplier, $m \equiv d Y_{t} / d G_{t}=y_{t} / g_{t}$ :

$$
m=1+(1-g) \vartheta_{g}
$$

With little algebra, and using the fact that $\Theta_{c}=\Phi_{r}^{-1}+(1-\bar{g}) \Theta_{g}$ when $U_{C N}=0$, the multiplier can be rewritten as

$$
m=\frac{1+\psi+(1-\bar{g}) \Phi_{r} \tilde{\delta} \Theta_{k}}{1+\psi+(1-\bar{g}) \Phi_{r} \Theta_{g}},
$$

where $\psi=\frac{(1-\rho)(1-\beta \rho)}{\kappa\left(\phi_{\pi}-\rho\right)} \geq 0$ is a parameter that captures the Keynesian features of this economy, i.e., nominal rigidity and monetary policy.

Denote by $m^{n}$ the neoclassical multiplier, that is, the multiplier obtained under fully flexible prices $\left(\kappa \rightarrow \infty\right.$ or, equivalently, $\psi=0$ ), and by $m_{u}$ the multiplier corresponding to the case where all public spending is unproductive $\left(\tilde{\delta} \Theta_{k}=0\right)$. These quantities are given by

$$
\begin{aligned}
m^{n} & =\frac{1+(1-\bar{g}) \Phi_{r} \tilde{\delta} \Theta_{k}}{1+(1-\bar{g}) \Phi_{r} \Theta_{g}}, \\
m_{u} & =\frac{1+\psi}{1+\psi+(1-\bar{g}) \Phi_{r} \Theta_{g}} .
\end{aligned}
$$

The following proposition summarizes the main properties of the spending multiplier in normal times.

Proposition 1 In normal times, the spending multiplier, $m$, is linearly increasing in the share of public investment, $\alpha$, and is larger than 1 if and only if

$$
\tilde{\delta} \Theta_{k} \geq \Theta_{g}
$$

In this case, we have

$$
m_{u} \leq 1 \leq m \leq m^{n}
$$

In order to get some intuition for the results stated in Proposition 1, it is useful to use equations (26), (27), and the fact that $E_{t} g_{t+1}=\rho g_{t}$, to express $E_{t} \pi_{t+1}$ and $E_{t} c_{t+1}$ as functions of $\pi_{t}$ and $c_{t}$

$$
\begin{aligned}
& E_{t} c_{t+1}=\rho c_{t} \\
& E_{t} \pi_{t+1}=\rho \pi_{t} .
\end{aligned}
$$



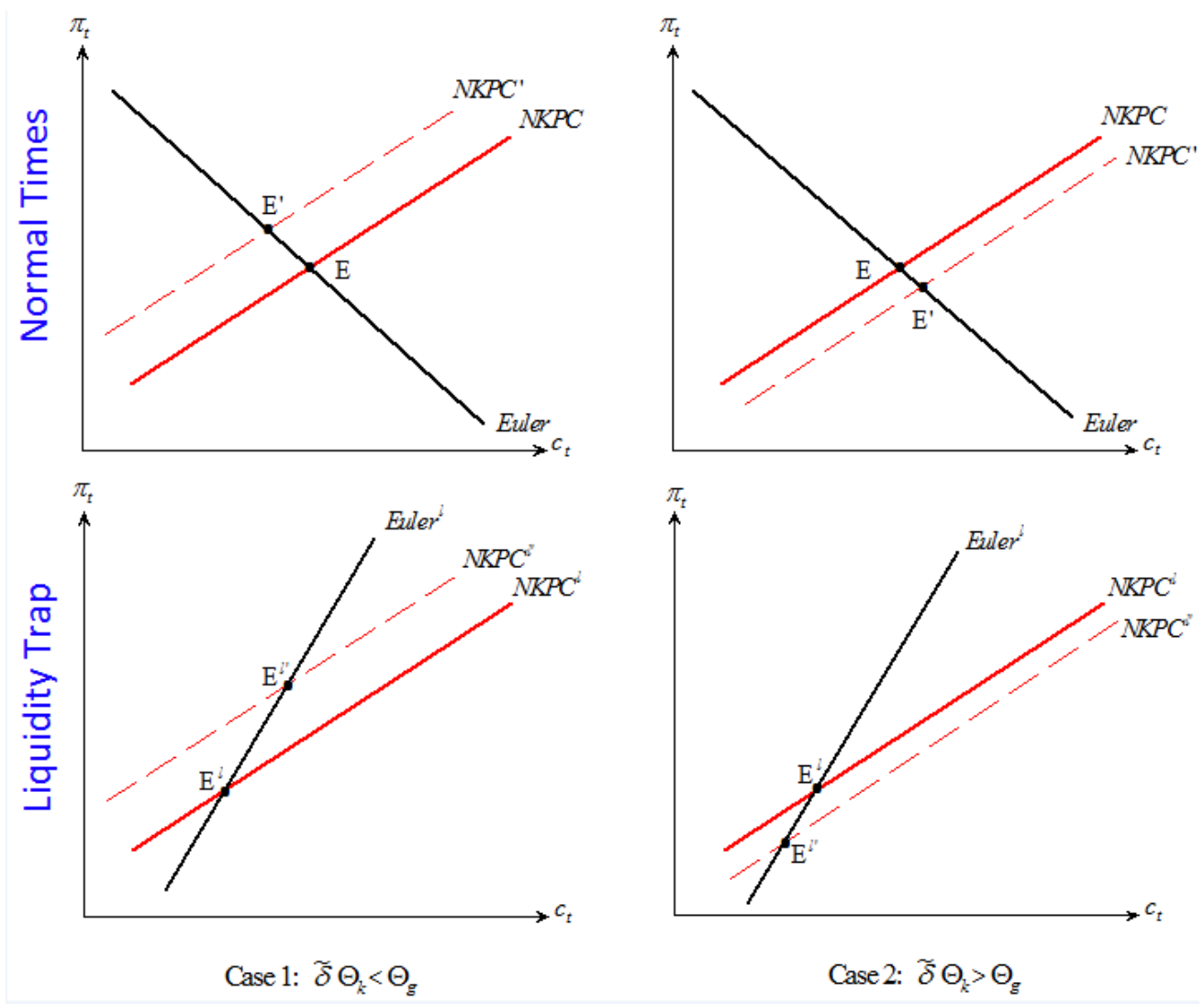

Figure 1: Graphical representation of the equilibrium in normal times and when the ZLB binds in a model with no time-to-build and full depreciation of public capital.

Inserting these expressions in (24) and (25), we obtain

$$
\begin{aligned}
c_{t} & =-\frac{\left(\phi_{\pi}-\rho\right) \Phi_{r}}{1-\rho} \pi_{t}, \\
\pi_{t} & =\frac{\kappa \Theta_{c}}{1-\beta \rho} c_{t}+\frac{\kappa\left(\Theta_{g}-\tilde{\delta} \Theta_{k}\right)}{1-\beta \rho} g_{t} .
\end{aligned}
$$

The upper panels of Figure 1 provide a graphical representation of these two equations in the $\left(c_{t}, \pi_{t}\right)$ plan. The curve labeled "Euler" corresponds to (31) and is downward sloping. The curve labeled "NKPC" corresponds to (32) and its positive slope implies a finite value of $\kappa$.

An increase in government spending leaves the Euler curve unchanged but shifts the NKPC. In the standard case where public spending is entirely unproductive, an increase in government expenditures raises aggregate demand, which in turn raises real marginal cost by a factor of $\Theta_{g}$ (see equation 25). As a result, the $N K P C$ shifts to the left, leading to an increase in inflation 
and a fall in consumption in equilibrium. This in turn yields a multiplier that is smaller than 1. Productive public spending, on the other hand, acts like a technology shock, raising aggregate supply and lowering real marginal cost by a factor of $\tilde{\delta} \Theta_{k}$. When $\tilde{\delta} \Theta_{k}<\Theta_{g}$, the latter effect is not strong enough to induce a fall in real marginal cost and the $N K P C$ still shifts to the left. In contrast, when $\tilde{\delta} \Theta_{k}>\Theta_{g}$, the supply-side effect dominates and, as a result, the NKPC shifts to the right. This yields an increase in consumption and a multiplier larger than 1 . The magnitude of the rightward shift in the NKPC depends positively on the term $\tilde{\delta} \Theta_{k}-\Theta_{g}$, which increases monotonically with $\alpha$. Moreover, as prices become less rigid (that is, as $\kappa$ increases), the $N K P C$ becomes steeper and shifts by a larger amount, thus implying a larger multiplier. The latter reaches its maximum value, $m^{n}$, when prices are fully flexible, i.e., when the slope of the $N K P C$ is infinite.

\subsection{The spending multiplier in a liquidity trap}

We now study the effects of a government spending shock under the assumption that the ZLB on the nominal interest rate binds. The ZLB becomes binding as a result of shock that raises the discount from $\beta$ to $\beta^{l}$. As in Christiano et al. (2011), Eggertsson (2011) and Woodford (2011), we assume that the discount factor can take only two possible values, $\beta$ and $\beta^{l}<\beta$, and evolves according to the following process:

$$
\begin{gathered}
\operatorname{Pr}\left[\beta_{t+1}=\beta^{l} \mid \beta_{t}=\beta^{l}\right]=p \\
\operatorname{Pr}\left[\beta_{t+1}=\beta^{l} \mid \beta_{t}=\beta\right]=0 .
\end{gathered}
$$

For simplicity, we also follow this literature by assuming that $g_{t}=g_{t}^{l}$ as long as the ZLB is binding and $g_{t}=0$ otherwise. Substituting $i_{t}=0$ in equation (17) and denoting by a superscript $l$ the values taken by the variables when the economy is in a liquidity trap, we obtain the following system:

$$
\begin{aligned}
c_{t}^{l} & =E_{t} c_{t+1}+\Phi_{r}\left(E_{t} \pi_{t+1}+r_{\beta}^{l}\right), \\
\pi_{t}^{l} & =\beta E_{t} \pi_{t+1}+\kappa\left(\Theta_{c} c_{t}^{l}+\left(\Theta_{g}-\tilde{\delta} \Theta_{k}\right) g_{t}^{l}\right) .
\end{aligned}
$$

The absence of an endogenous state variable in this system means that whenever the economy leaves the ZLB state, it jumps immediately to its steady state. Thus, $E_{t} c_{t+1}=p c_{t}^{l}$ and $E_{t} \pi_{t+1}=p \pi_{t}^{l}$. 
Solving for $c_{t}^{l}$ and $\pi_{t}^{l}$ yields

$$
\begin{aligned}
c_{t}^{l} & =\frac{p \kappa\left(\Theta_{g}-\tilde{\delta} \Theta_{k}\right) \Phi_{r}}{(1-p)(1-\beta p)-p \kappa \Phi_{r} \Theta_{c}} g_{t}^{l}+\frac{\kappa(1-\beta p) \Phi_{r}}{(1-p)(1-\beta p)-p \kappa \Phi_{r} \Theta_{c}} r_{\beta}^{l}, \\
\pi_{t}^{l} & =\frac{\kappa(1-p)\left(\Theta_{g}-\tilde{\delta} \Theta_{k}\right)}{(1-p)(1-\beta p)-p \kappa \Phi_{r} \Theta_{c}} g_{t}^{l}+\frac{\kappa \Phi_{r} \Theta_{c}}{(1-p)(1-\beta p)-p \kappa \Phi_{r} \Theta_{c}} r_{\beta}^{l},
\end{aligned}
$$

where $(1-p)(1-\beta p)-p \kappa \Phi_{r} \Theta_{c}>0$ is a necessary condition for stability. If this condition is violated, the ZLB does not bind.

The spending multiplier associated with the ZLB state, $m^{l}$, is given by

$$
m^{l}=\frac{\psi^{l}-1-(1-g) \Phi_{r} \tilde{\delta} \Theta_{k}}{\psi^{l}-1-(1-\bar{g}) \Phi_{r} \Theta_{g}}
$$

where $\psi^{l}=\frac{(1-p)(1-\beta p)}{p \kappa}>0 .{ }^{8}$ In the case where public spending is entirely unproductive $\left(\tilde{\delta} \Theta_{k}=0\right)$, the multiplier, denoted by $m_{u}^{l}$, is given by

$$
m_{u}^{l}=\frac{\psi^{l}-1}{\psi^{l}-1-(1-\bar{g}) \Phi_{r} \Theta_{g}} .
$$

The following proposition summarizes the main properties of the multiplier in a liquidity trap.

Proposition 2 When the $Z L B$ binds, the spending multiplier, $m^{l}$, is linearly decreasing in the share of public investment, $\alpha$, and is larger than 1 if and only if

$$
\tilde{\delta} \Theta_{k} \leq \Theta_{g}
$$

In this case, we have

$$
m^{n}<m \leq 1 \leq m^{l} \leq m_{u}^{l}
$$

Again, the intuition for these results can be understood by examining how the Euler and NKPC equations are affected by the increase in public spending. Substituting the conditional expectations of $c_{t+1}$ and $\pi_{t+1}$ in (34) and in (35), we obtain

$$
\begin{aligned}
c_{t}^{l} & =\frac{p \Phi_{r}}{1-p} \pi_{t}^{l}, \\
\pi_{t}^{l} & =\frac{\kappa \Theta_{c}}{1-\beta p} c_{t}^{l}+\frac{\kappa\left(\Theta_{g}-\tilde{\delta} \Theta_{k}\right)}{1-\beta p} g_{t}^{l} .
\end{aligned}
$$

These two curves are represented graphically in the bottom panels of Figure 1, and are labeled Euler ${ }^{l}$ and $N K P C^{l}$, respectively. Note that the former is upward sloping when the ZLB binds. Intuitively,

${ }^{8}$ Note that the stability condition stated above implies that $\psi^{l}>1+(1-\bar{g}) \Phi_{r} \Theta_{g}$. 
higher current inflation leads to a rise in expected inflation and since the nominal interest rate is constant (at zero), the real interest rate must fall, thus causing an increase in consumption, ceteris paribus. In this case, an increase in public spending will raise consumption in equilibrium only to the extent that it shifts $N K P C^{l}$ to the left, which requires that the demand-side effect of public spending dominates its supply-side effect, i.e., $\Theta_{g} \geq \tilde{\delta} \Theta_{k}$ (see the bottom left panel of Figure 1). The largest increase in consumption - and therefore the largest multiplier - is obtained when the fraction of public investment, $\alpha$, is nil. On the other hand, the larger this fraction, the further $N K P C^{l}$ shifts to the right and the smaller the value of the multiplier.

\subsection{Quantitative analysis}

So far, the discussion about the size of the spending multiplier has remained mostly qualitative. The purpose of this section is to provide a quantitative assessment of the size of the spending multiplier and its dependence on the share of public investment in a stimulus plan, both in normal times and when the ZLB binds. To this end, we need to specify functional forms for the utility and production functions and to assign values to the model parameters. For ease of comparison with the results obtained by Christiano et al. (2011), we adopt the same functional form for preferences and consider a production function that nests their specification.

The utility function is given by

$$
\begin{aligned}
U\left(C_{t}, N_{t}\right) & =\frac{\left(C_{t}^{\gamma}\left(1-N_{t}\right)^{1-\gamma}\right)^{1-\sigma}-1}{1-\sigma} & & \text { if } \sigma \neq 1 \\
& =\gamma \ln C_{t}+(1-\gamma) \ln \left(1-N_{t}\right) & & \text { if } \sigma=1
\end{aligned}
$$

where $\sigma>0$ and $0<\gamma \leq 1$.

The production function is given by

$$
F\left(N_{t}, K_{t}\right)=N_{t}^{a} K_{t}^{b}
$$

where $0 \leq a, b \leq 1$. This specification nests the linear technology assumed by Christiano et al. (2011) as a special case in which $a=1$ and $b=0$. The expressions of the composite parameters $\Phi_{r}$,

$\Phi_{g}, \Phi_{k}, \Theta_{g}, \Theta_{k}$, and $\Theta_{c}$ implied by the functional forms assumed above are summarized in Table 1 (see Appendix A.4 for the derivation).

We closely follow Christiano et al. (2011)'s calibration. In particular, we use their values for $\beta, \gamma, a, \kappa, \phi_{\pi}$, and $\rho$, as well as for the steady-state ratio of government spending to output, $\bar{g}$. 
Table 1: Expressions of the composite parameters

\begin{tabular}{cccccc}
\hline \hline$\Phi_{r}$ & $\Phi_{g}$ & $\Phi_{k}$ & $\Theta_{c}$ & $\Theta_{g}$ & $\Theta_{k}$ \\
\hline 1 & $\frac{\gamma(\sigma-1)}{1-\bar{g}}$ & $\frac{b \gamma(\sigma-1)}{1-\bar{g}}$ & $\frac{\kappa}{1-\gamma}$ & $\frac{\kappa}{1-\bar{g}} \frac{\gamma}{1-\gamma}$ & $b \kappa\left(1+\frac{1}{1-\bar{g}} \frac{\gamma}{1-\gamma}\right)$
\end{tabular}

However, we set $\sigma=1$ to ensure that $U_{C N}()=$.0 , as assumed in the simple case discussed above. ${ }^{9}$ We also need to assign values to two additional parameters that are absent from Christiano et al. (2011)'s model: the steady-state share of public investment in total public spending, $\bar{\alpha}$, and the elasticity of output with respect to public capital, $b$. The former can be approximated by the historical average ratio of public investment to total public spending, which is roughly 0.23 in the US (from 1947 to 2012), so we set $\bar{\alpha}=0.23$. The latter is less straightforward to parameterize as available empirical estimates of $b$ vary considerably depending on the methodology and sample period considered. Using a meta-analysis of existing empirical studies, Bom \& Ligthart (2013) reach an average estimate of 0.08 . This value lies in between the two values considered by Leeper et al. (2010): 0.05 and 1. Therefore, we set $b=0.08$ in our benchmark calibration. The chosen parameter values are summarized in Table 2 .

Table 2: Benchmark parameter values

\begin{tabular}{lr}
\hline \hline Discount factor & $\beta=0.99$ \\
Preference parameter & $\sigma=1$ \\
Preference parameter & $\gamma=0.29$ \\
Elasticity of output w.r.t labor & $a=1$ \\
Elasticity of output w.r.t public capital & $b=0.08$ \\
Elasticity of inflation w.r.t real marginal cost & $\kappa=0.03$ \\
Inflation feedback parameter & $\phi_{\pi}=1.5$ \\
Autocorrelation of the public spending shock & $\rho=0.8$ \\
Steady-state ratio of public spending to output & $\bar{g}=0.2$ \\
Steady-state ratio of public investment to total public spending & $\bar{\alpha}=0.23$ \\
\hline \hline
\end{tabular}

Using the values reported in Table 2, we compute the spending multiplier as a function of $\alpha$ in normal times $(m)$ and when the ZLB binds $\left(m^{l}\right)$. The results are shown in Figure 2. The figure also reports the neoclassical multiplier, $m^{n}$, defined in (29). Figure 2 confirms that, in normal times, the spending multiplier in the new-Keynesian model increases linearly with $\alpha$, from 0.88 when $\alpha=0$

\footnotetext{
${ }^{9}$ Christiano et al. (2011) set $\sigma=2$ in their benchmark calibration. See Bilbiie (2011) and Monacelli \& Perotti (2008) for an analysis of the effects of public spending under the assumption of non-separability between consumption and leisure.
} 
to 1.5 when $\alpha=1$. When the ZLB binds, on the other hand, the multiplier declines linearly from 2.26 when $\alpha=0$ to -4.2 when $\alpha=1$. When $\alpha$ exceeds 35 percent, the spending multiplier exceeds 1 in normal times and is negative when the ZLB binds. Interestingly, the value of $\alpha$ for which $m=m^{l}=m^{n}=1$ is equal to 19.4 percent, ${ }^{10}$ which is even lower than the steady-state share of public investment in total public expenditures $(\bar{\alpha})$. This suggests that the supply-side effects of public spending can be substantial even with a modest fraction of productive public spending when the latter affects production contemporaneously.

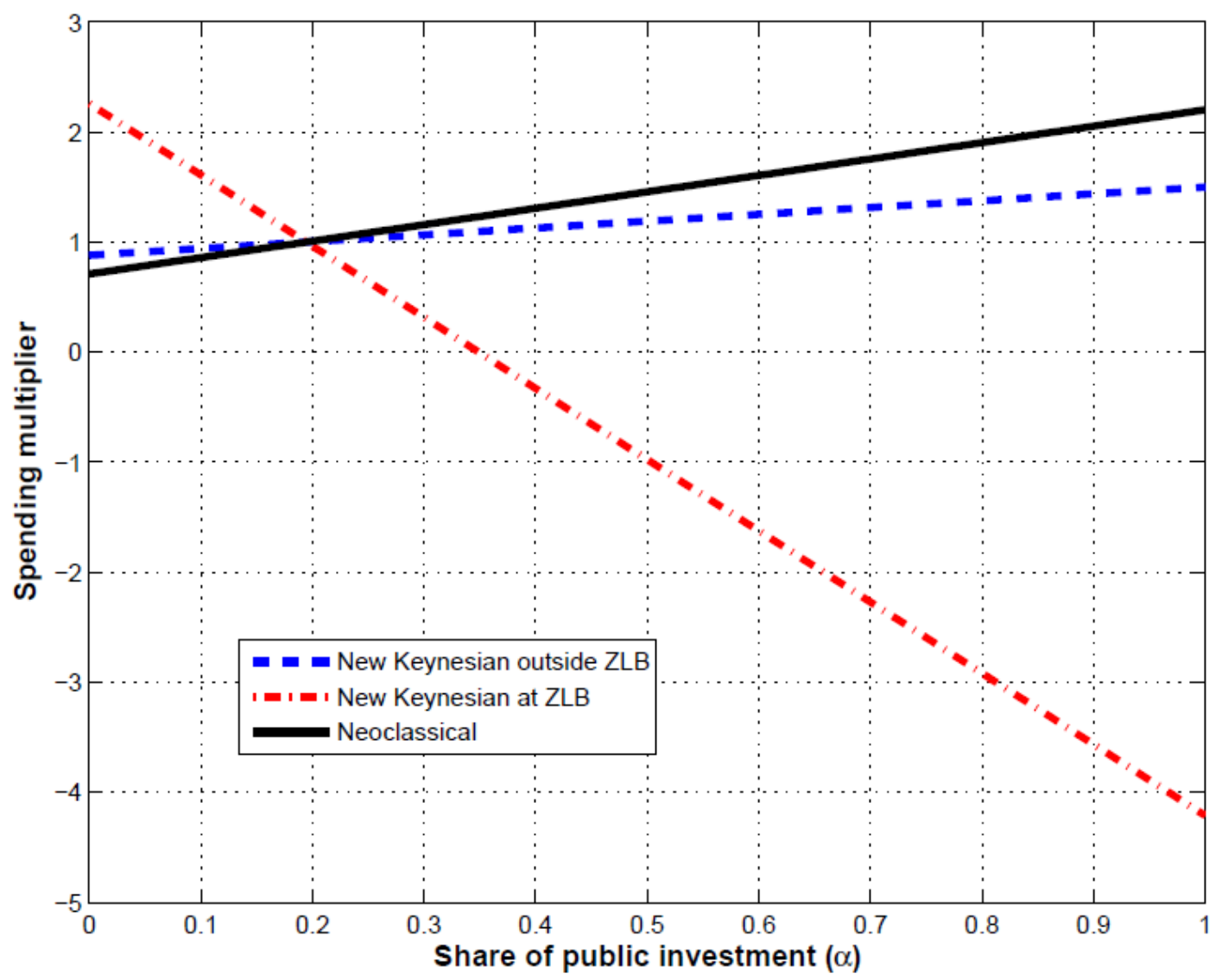

Figure 2: Spending multiplier as a function of the share of public investment in a model with no time-to-build and full depreciation of public capital.

It is important to emphasize that the assumption of additive separability is only made for analytical tractability and is not essential for the results outlined so far. With $\sigma=2$, we obtain very similar patterns for $m, m^{l}$ and $m^{n}$ to those depicted in Figure 2. Of course, the numerical

\footnotetext{
${ }^{10}$ This is the value of $\alpha$ such that the aggregate supply and aggregate demand effects of public spending exactly offset each other $\left(\Theta_{g}=\tilde{\delta} \Theta_{k}\right)$, leaving and private spending and inflation unchanged.
} 
values of the multiplier will be slightly different, ${ }^{11}$ but the general message remains. ${ }^{12}$

\section{The Spending Multiplier in a Model with Public Investment and Time to Build}

The simplifying assumptions considered in the previous section, namely that public investment becomes immediately productive and public capital fully depreciates after one period, albeit unrealistic, are nonetheless insightful about the role of investment in this economy. Under these assumptions, the supply-side effect of public spending is largest on impact (i.e., at the time of the shock), thus implying that the spending multiplier at the ZLB may become small and even negative when the fraction of public investment in a stimulus plan is sufficiently large.

In this section, we relax these two assumptions and consider a more general version of the model with time to build $(T \geq 1)$ and an empirically plausible value of the depreciation rate of public capital, $\delta$. As we did in section 3 , we first study the effects of public capital in normal times before turning to those occurring when the ZLB binds.

\subsection{The spending multiplier in normal times}

In normal times, the model is given by equation (17)-(20), with $i_{t}=\phi_{\pi} \pi_{t}$. Under the assumption that $\phi_{\pi}>1$, and given the process (13), the unique linear rational expectation solution of the system above is given by

$$
\begin{aligned}
c_{t} & =\vartheta_{k} k_{t-1}+\sum_{\tau=0}^{T} \vartheta_{g}^{\tau} g_{t-\tau}, \\
\pi_{t} & =\zeta_{k} k_{t-1}+\sum_{\tau=0}^{T} \zeta_{g}^{\tau} g_{t-\tau},
\end{aligned}
$$

where the coefficients $\vartheta_{k}, \zeta_{k}, \vartheta_{g}^{\tau}$, and $\zeta_{g}^{\tau}(\tau=0, \ldots, T)$ are given in Appendix A.5.1 . The impact multiplier, $m^{0}$, is then given by

$$
m^{0}=1+(1-\bar{g}) \vartheta_{g}^{0}
$$

In order to study the way in which $m^{0}$ varies with the share of public investment, $\alpha$, it is easier to consider again the case with additively separable preferences $\left(U_{C N}()=0.\right)$. Figure 3 shows this relationship for different time-to-build delays, $T$, ranging from 1 to 12 quarters. The reported

\footnotetext{
${ }^{11}$ In particular, the values of $m$ and $m^{l}$ obtained when $\alpha=0$ (i.e., $m_{u}$ and $m_{u}^{l}$, respectively) are identical to those reported by Christiano et al. (2011) (i.e., 1.05 and 3.7, respectively.)

${ }^{12}$ These results are not reported but are available upon request.
} 
values for $m^{0}$ are computed using the parameter values presented in Table 2 and a value of 0.02 for the depreciation rate of public capital, $\delta$ (an in Leeper et al. (2010)). The first message conveyed by this figure is that the spending multiplier is monotonically increasing in $\alpha$ when the time to build is relatively short ( $T \leq 8$ quarters) and monotonically decreasing in $\alpha$ when the time to build is relatively long.

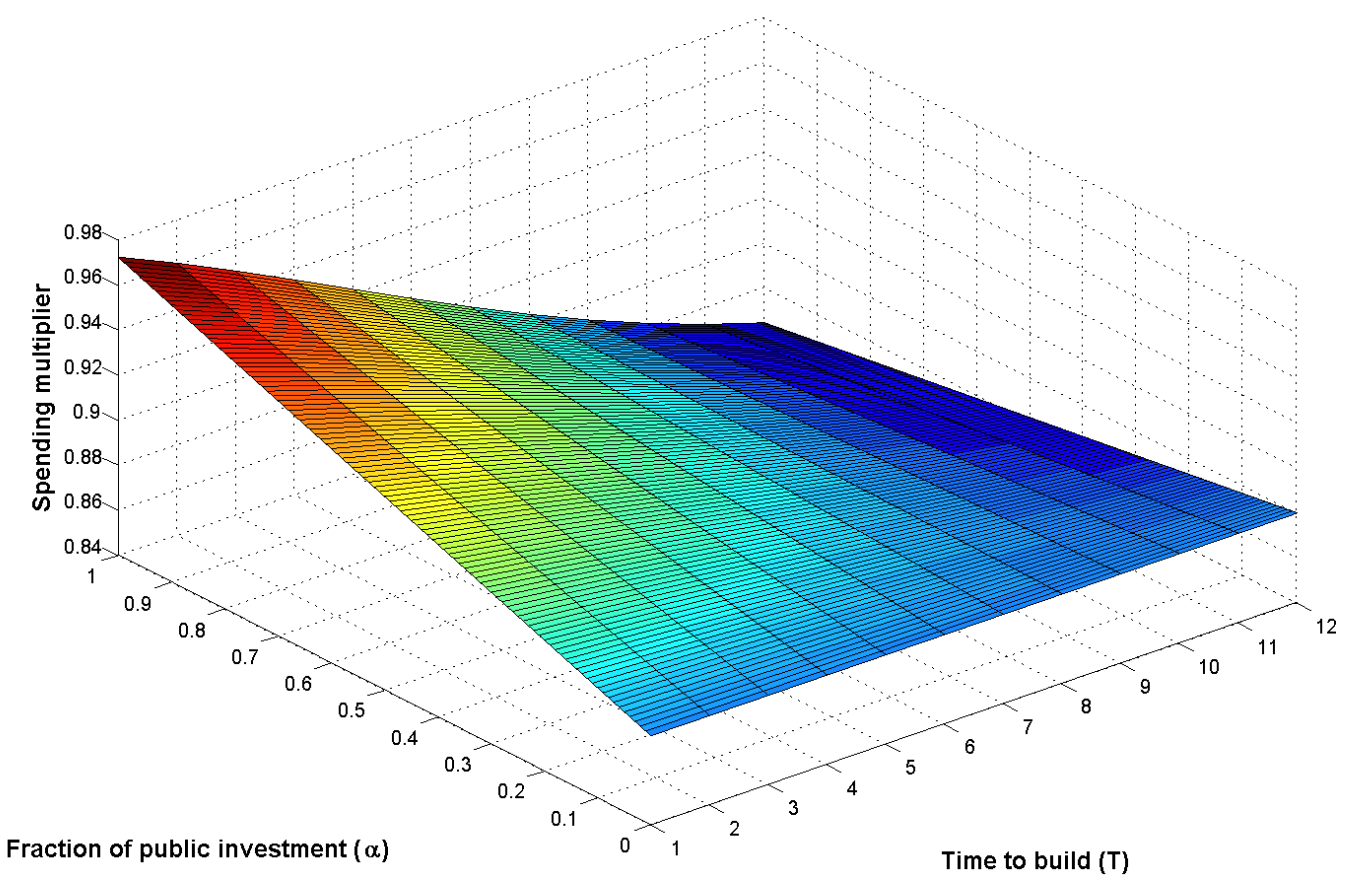

Figure 3: Spending multiplier as a function of the share of public investment and time-to-build delay in normal times.

In order to understand the intuition behind this result, it is useful to recall that the size of the multiplier depends on the response of consumption, which in our sticky-price economy depends on the deviation of the long-term ex ante real interest rate from its steady-state value, $r_{t}^{L T} \equiv$ 
$E_{t} \sum_{\tau=0}^{\infty}\left(i_{t+\tau}-\pi_{t+1+\tau}-r_{\beta}\right) .{ }^{13}$ The latter is in turn determined by the entire path of (expected) inflation and ultimately by the dynamic response of real marginal cost. With $T>0$, the increase in public investment raises the stock of capital in subsequent periods and this has two opposite effects on future real marginal costs: $(i)$ a negative (supply-side) effect reflecting the expected increase in the marginal productivity of labor, and $(i i)$ a positive effect stemming from the increase in future aggregate demand due to the increase in households' expected wealth. The demand side effect tends to amplify the response of inflation at short horizons to an extent that depends positively on the share of public investment in the stimulus, $\alpha$, whereas the supply side effect tends to dampen the response of inflation at longer horizons, also to an extent that increases with $\alpha$. When the time to build is short, the supply-side effect quickly comes into play so that expected inflation is mainly driven by future declines in real marginal cost. In this case, the long-term real interest rate rises less in response to the increase in public spending as $\alpha$ becomes larger. This is why the consumption response, and therefore the spending multiplier, are increasing in $\alpha$ when $T$ is sufficiently short. Figure 4 illustrates this mechanism. The figure depicts the impulse responses to a government spending shock for $T=1$ and $\alpha=\{0,0.5,1\}$. As $\alpha$ increases, inflation, the nominal and the real interest rates rise more during the first 7 quarters after the shock, but fall more sharply for a prolonged period of time afterwards. As a result, the rise in the long run-real interest rate and the fall in consumption are smaller the larger is $\alpha$.

As $T$ increases, the supply-side effect of productive public spending is further delayed and the dynamic response of inflation becomes increasingly driven by current and futures increases in aggregate demand. In response to the shock, the long-term real interest rate thus rises more, consumption falls more, and the spending multiplier declines as $\alpha$ increases. This is illustrated in Figure 5, which shows the dynamic effects of the government spending shock for $T=12$.

The second observation that emerges from Figure 3 is that the spending multiplier is always lower than unity. Thus, under plausible parameter values and time-to-build delays, the spending multiplier in normal times remains numerically close to that predicted by a standard model in which all public spending is unproductive.

\footnotetext{
${ }^{13}$ Iterating equation (21) forward yields$$
c_{t}=\lim _{j \rightarrow \infty} E_{t} c_{t+j}-\Phi_{r} r_{t}^{L T}
$$

In response to a transitory shock, $\lim _{j \rightarrow \infty} E_{t} c_{t+j}=0$ and current consumption moves in an opposite direction to $r_{t}^{L T}$ (since $\left.\Phi_{r}>0\right)$.
} 

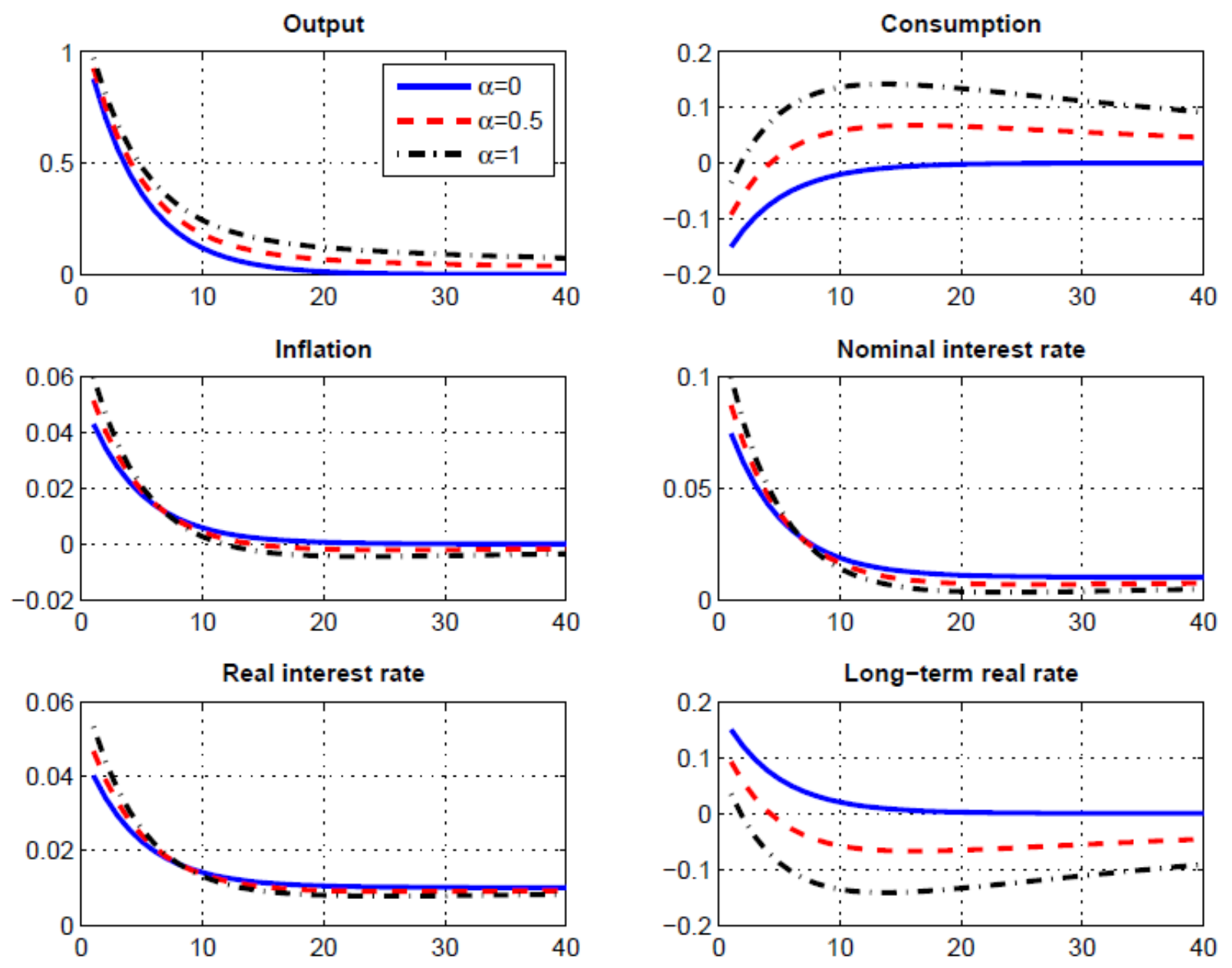

Figure 4: Impulse response functions to a government spending shock in normal times, $T=1$.

Note: The nominal and real interest rates are expressed in level form whereas the long-term real interest rate is expressed as a deviation from its steady-state value. 

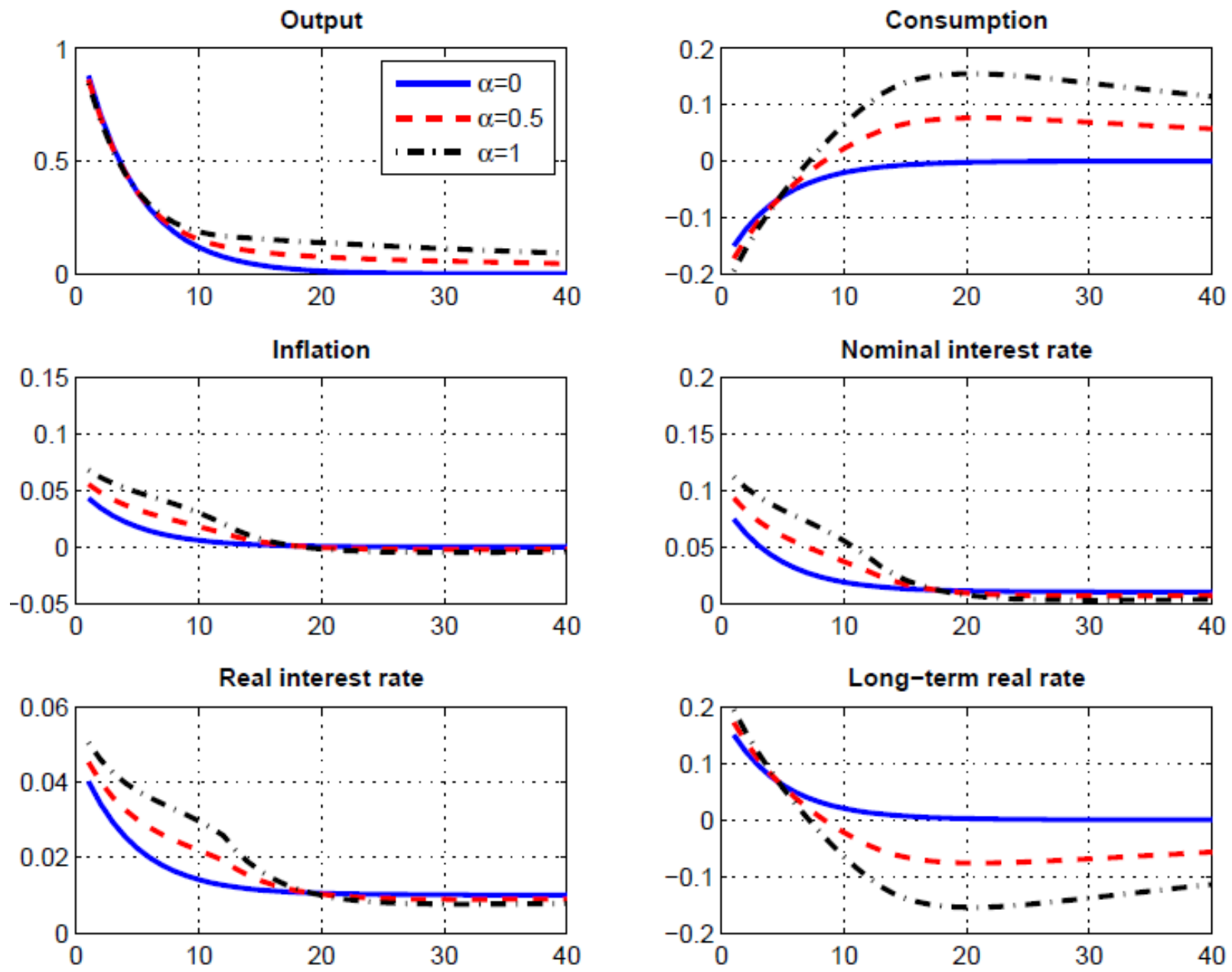

Figure 5: Impulse response functions to a government spending shock in normal times, $T=12$.

Note: The nominal and real interest rates are expressed in level form whereas the long-term real interest rate is expressed as a deviation from its steady-state value. 


\subsection{The spending multiplier in a liquidity trap}

When the ZLB binds, the model is given by equation (17)-(20), with $i_{t}=0$. As before, we assume that the discount factor remains high, at $\beta^{l}$, with probability $p$ and returns permanently to its steady-state value, $\beta$, with probability $1-p$. We also assume that $g_{t+1}=g_{t}>0$ if the ZLB is still binding in $t+1$ and $g_{t+1}=0$ otherwise. Note that the economy does not immediately return to steady state when the ZLB ceases to bind, as the stock of public capital continues to adjust and converges to its steady state only gradually. Conditional on the economy being in the ZLB state, the expected value of a given variable in $t+1$ is an average of its possible values in $t+1$ inside and outside the liquidity trap, weighted by the respective probabilities of being in these two states. The linear rational expectation solution of the model when the ZLB binds is given by

$$
\begin{aligned}
& c_{t}=\vartheta_{i}^{l} r_{\beta}^{l}+\vartheta_{k}^{l} k_{t-1}+\sum_{\tau=0}^{T} \vartheta_{g}^{l, \tau} g_{t-\tau}, \\
& \pi_{t}=\zeta_{i}^{l} r_{\beta}^{l}+\zeta_{k}^{l} k_{t-1}+\sum_{\tau=0}^{T} \zeta_{g}^{l, \tau} g_{t-\tau},
\end{aligned}
$$

where the coefficients $\vartheta_{k}^{l}, \zeta_{k}^{l}, \vartheta_{g}^{l, \tau}$, and $\zeta_{g}^{l, \tau}(\tau=0, \ldots, T)$ are given in Appendix A.5.2 . The impact spending multiplier when the ZLB binds, $m^{l, 0}$, is

$$
m^{l, 0}=1+(1-\bar{g}) \vartheta_{g}^{l, 0}
$$

Focusing again on the case with additively separable preferences $\left(U_{C N}=0\right)$, we compute $m^{l, 0}$ as a function of $\alpha$ and $T$ using the parameter values in Table 2 and $\delta=0.02$. The results are depicted in Figure 6. They indicate that the spending multiplier is decreasing in $\alpha$ when the time to build is shorter than 4 quarters and increasing in $\alpha$ for longer implementation delays. Intuitively, an increase in government spending initially raises aggregate demand and expected inflation. Since the nominal interest rate is stuck at zero, this translates into a fall in the real interest rate during the first few quarters after the shock. When $T$ is sufficiently short, the deflationary (supply-side) effect associated with the increase in productive public capital comes about quickly after the initial shock, attenuating the fall in the real interest rate to an extent that depends positively on $\alpha$. This in turn means that the long-term real interest rate falls less, thus implying a lower multiplier, as $\alpha$ increases.

As $T$ increases, the deflationary pressure brought about the increase in public capital is further delayed, and so is its positive effect on the real interest rate. At the same time, the positive wealth 


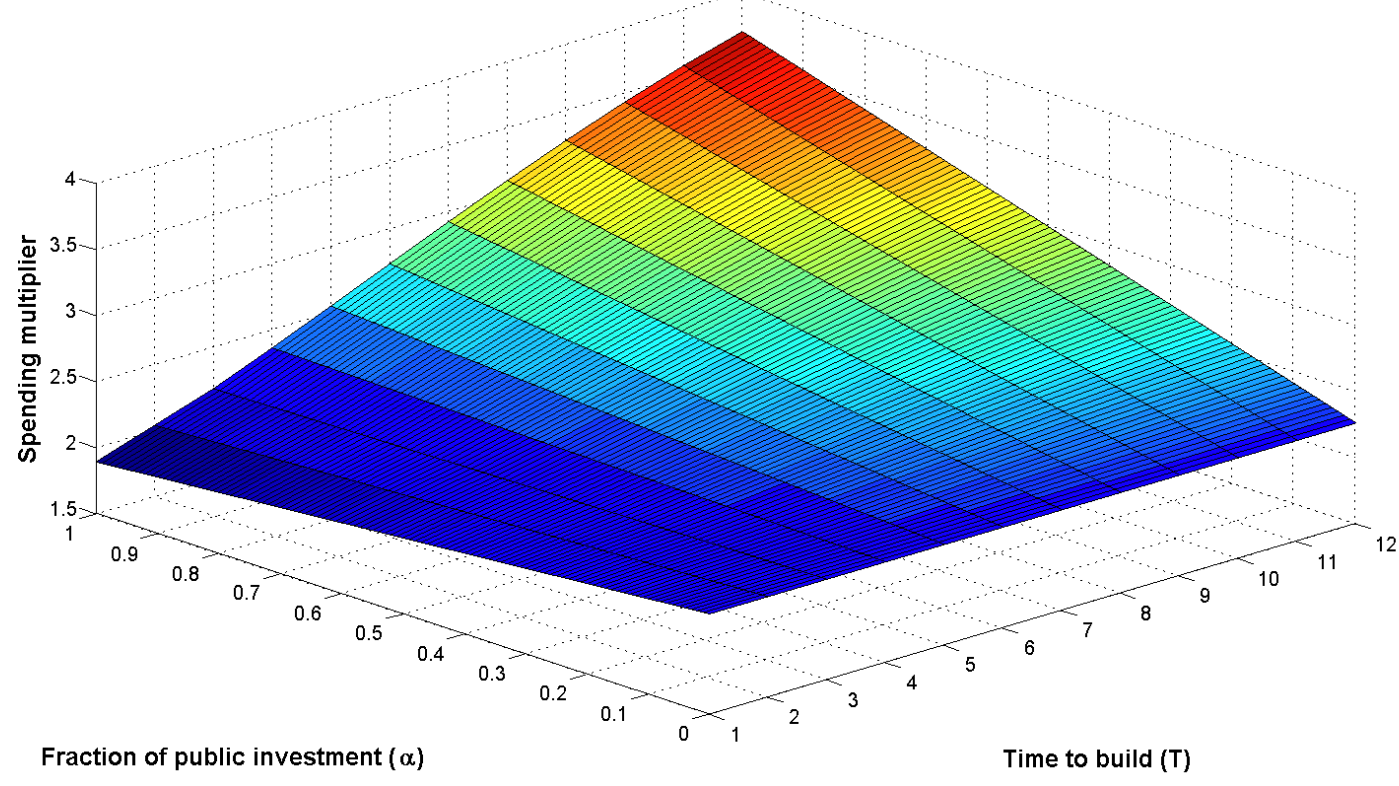

Figure 6: Spending multiplier as a function of the share of public investment and time-to-build delay in a liquidity trap.

effect associated with the expected increase in labor income further reinforces the fall in the real interest rate at the time of the shock and during the subsequent periods, and this effect is larger the larger is $\alpha$. When $T$ is sufficiently long, the net effect is a fall in the long-term real interest rate that is larger the larger is $\alpha$. This is why the spending multiplier is increasing in $\alpha$ when the implementation delay is long.

Figure 6 shows that the spending multiplier can be substantially large at the ZLB when a large fraction of public spending is invested in public capital and when the implementation delay is relatively long. When $\alpha=1$ and $T=12$, the multiplier is roughly 4.5 times larger than in normal times. 


\subsection{Robustness: the case of non-separable preferences}

For ease of interpretation, the results presented in Figures 4-6 are generated under the assumption of additively separable preferences $\left(U_{C N}=0\right)$. In this section, we study the more general case in which consumption and leisure are substitutes. This is achieved by choosing a strictly positive value of $\sigma$ that is different from 1. Figures 7 and 8 (in Appendix A.6) show the spending multiplier as a function of $\alpha$ and $T$ in normal times and when the ZLB binds, respectively, for $\sigma=2$, the value imposed by Christiano et al. (2011).

The two figures show that the spending multiplier is larger for any given value of $\alpha$ and $T$ than that obtained under separable preferences. Intuitively, the increase in labor demand triggered by the increase in public spending reduces leisure and raises the marginal utility of consumption, ceteris paribus. This channel mitigates the negative wealth effect associated with the increase in taxes needed to finance the increase in government spending. Thus, consumption falls less and may even increase in response to the public spending shock when substitutability between consumption and leisure is sufficiently strong, which is the case when $\sigma=2$. This in turn implies that the shape of the relationship between the multiplier and $\alpha$ and $T$ is preserved when one considers alternative values of $\sigma$. Under non-separable preferences, the spending multiplier at the ZLB is more than 5 times larger than in normal times when $\alpha=1$ and $T=12$.

\section{Conclusion}

The main lesson from the literature on the effects of fiscal policy in a liquidity trap is that policies that stimulate aggregate demand can have substantially larger effects when the ZLB binds than in normal times. On the other hand, policies that raise the natural level of output may depress economic activity even further in a liquidity trap (Eggertsson (2011)). When a fraction of public spending is invested in infrastructure, and to the extent that public capital raises the marginal productivity of private inputs, an increase in government spending raises both aggregate demand and future natural levels of output. This policy affects current and expected inflation in two conflicting ways, so that the size of the spending multiplier depends on the fraction of public investment in a stimulus plan and on the implementation delays associated with the completion of public investment projects.

This paper has shown that, in states where the ZLB binds, the spending multiplier is smaller the larger the share of public investment in a stimulus plan when the time-to-build delay is relatively short-less than 4 quarters under our benchmark calibration. In contrast, with sufficiently long 
time-to-build delays, this relationship is reversed and the spending multiplier can be twice as large as the multiplier associated with unproductive public expenditures. These results suggest that the conventional wisdom that fiscal stimulus plans should prioritize shovel ready investment projects may not hold when the economy is stuck in a liquidity trap. A formal analysis of the normative aspects of fiscal policy - including the optimal allocation of public spending - when the ZLB binds, however, ought to be welfare-based, which requires knowledge of the way in which the different categories of public spending affect agents' utility. We leave this task for future research. 


\section{References}

Auerbach, A. J. \& Gorodnichenko, Y. (2012). Measuring the output responses to fiscal policy. American Economic Journal: Economic Policy, 4(2), 1-27.

Bachmann, R. \& Sims, E. R. (2012). Confidence and the transmission of government spending shocks. Journal of Monetary Economics, 59(3), 235-249.

Barro, R. J. (1990). Government spending in a simple model of endogenous growth. Journal of Political Economy, 98(5), S103-26.

Barro, R. J. \& Redlick, C. J. (2011). Macroeconomic effects from government purchases and taxes. The Quarterly Journal of Economics, 126(1), 51-102.

Baxter, M. \& King, R. G. (1993). Fiscal policy in general equilibrium. American Economic Review, $83(3), 315-34$.

Bilbiie, F. O. (2011). Nonseparable preferences, frisch labor supply, and the consumption multiplier of government spending: One solution to a fiscal policy puzzle. Journal of Money, Credit and Banking, 43(1), 221-251.

Blanchard, O. \& Perotti, R. (2002). An empirical characterization of the dynamic effects of changes in government spending and taxes on output. The Quarterly Journal of Economics, 117(4), 13291368.

Bom, P. R. \& Ligthart, J. E. (2013). What have we learned from three decades of research on the productivity of public capital? Journal of Economic Surveys, (pp. n/a-n/a).

Bouakez, H., Chihi, F., \& Normandin, M. (2013). Measuring the Effects of Fiscal Policy. Mimeo, Institute of Applied Economics and CIRPÉE, HEC Montréal.

Christiano, L., Eichenbaum, M., \& Rebelo, S. (2011). When is the government spending multiplier large? Journal of Political Economy, 119(1), 78 - 121.

Eggertsson, G. B. (2011). What fiscal policy is effective at zero interest rates? In NBER Macroeconomics Annual 2010, Volume 25, NBER Chapters (pp. 59-112). National Bureau of Economic Research, Inc. 
Fatás, A. \& Mihov, I. (2001). The Effects of Fiscal Policy on Consumption and Employment: Theory and Evidence. CEPR Discussion Papers 2760, C.E.P.R. Discussion Papers.

Galí, J., López-Salido, J. D., \& Vallés, J. (2007). Understanding the effects of government spending on consumption. Journal of the European Economic Association, 5(1), 227-270.

Hall, R. E. (2009). By How Much Does GDP Rise if the Government Buys More Output? NBER Working Papers 15496, National Bureau of Economic Research, Inc.

Kydland, F. E. \& Prescott, E. C. (1982). Time to build and aggregate fluctuations. Econometrica, $50(6), 1345-70$.

Leeper, E. M., Walker, T. B., \& Yang, S.-C. S. (2010). Government investment and fiscal stimulus. Journal of Monetary Economics, 57(8), 1000-1012.

Linnemann, L. \& Schabert, A. (2006). Productive government expenditure in monetary business cycle models. Scottish Journal of Political Economy, 53(1), 28-46.

Mertens, K. \& Ravn, M. O. (2010). Fiscal Policy in an Expectations Driven Liquidity Trap. CEPR Discussion Papers 7931, C.E.P.R. Discussion Papers.

Monacelli, T. \& Perotti, R. (2008). Fiscal Policy, Wealth Effects and Markups. CEPR Discussion Papers 7099, C.E.P.R. Discussion Papers.

Mountford, A. \& Uhlig, H. (2009). What are the effects of fiscal policy shocks? Journal of Applied Econometrics, 24(6), 960-992.

Perotti, R. (2005). Estimating the effects of fiscal policy in oecd countries. Proceedings.

Perotti, R. (2008). In search of the transmission mechanism of fiscal policy. In NBER Macroeconomics Annual 2007, Volume 22, NBER Chapters (pp. 169-226). National Bureau of Economic Research, Inc.

Ramey, V. A. (2011). Identifying government spending shocks: It's all in the timing. The Quarterly Journal of Economics, 126(1), 1-50.

Ramey, V. A. \& Shapiro, M. D. (1998). Costly capital reallocation and the effects of government spending. Carnegie-Rochester Conference Series on Public Policy, 48(1), 145-194. 
Woodford, M. (2011). Simple analytics of the government expenditure multiplier. American Economic Journal: Macroeconomics, 3(1), 1-35. 


\section{A Appendix}

\section{A.1 Summary of the model}

The model equilibrium conditions are

$$
\begin{aligned}
Y_{t} & =C_{t}+G_{t}, \\
\Delta_{t} Y_{t} & =F\left(N_{t}, K_{t}\right) \\
\frac{1}{1+i_{t}} & =\beta_{t+1} E_{t}\left(\frac{U_{C}\left(C_{t+1}, N_{t+1}\right)}{U_{C}\left(C_{t}, N_{t}\right)} \frac{P_{t}}{P_{t+1}}\right), \\
W_{t} & =-\frac{U_{N}\left(C_{t}, N_{t}\right)}{U_{C}\left(C_{t}, N_{t}\right)} \\
0 & =E_{t} \sum_{s=0}^{\infty} \phi^{s} Q_{t, t+s} X_{t, t+s}\left(P_{t}^{o}-\mu M C_{t, t+s}\right), \\
P_{t}^{1-\theta} & =(1-\phi)\left(P_{t}^{o}\right)^{1-\theta}+\phi P_{t-1}^{1-\theta}, \\
K_{t} & =(1-\delta) K_{t-1}+G_{t-T}^{i}, \\
i_{t} & =\max \left(0 ; \ln \beta^{-1}+\phi_{\pi} \ln \frac{P_{t}}{P_{t-1}}\right),
\end{aligned}
$$

where

$$
\begin{aligned}
\Delta_{t} & =J\left(\int J^{-1}\left[\left(\frac{P_{t}(z)}{P_{t}}\right)^{-\theta}\right] d z\right) \\
Q_{t, t+s} & =d_{t+s} U_{C}\left(C_{t+s}, N_{t+s}\right) / d_{t} U_{C}\left(C_{t}, N_{t}\right), \\
M C_{t, t+s} & =\frac{(1-\tau) \mathcal{W}_{t+s}}{F_{N}\left(N_{t, t+s}, K_{t+s}\right)} .
\end{aligned}
$$

\section{A.2 Steady state}

Using equations (A.1) to (A.8) evaluated at steady state, we obtain a system of three equations that uniquely determine private consumption, hours worked and public capital in steady state. These quantities are all we need to compute the log-linearized version of the model.

$$
\begin{aligned}
C & =(1-\bar{g}) F(N, K), \\
-\frac{U_{N}(C, 1-N)}{U_{C}(C, 1-N)} & =\frac{\theta-1}{(1-\tau) \theta} F_{N}(N, K), \\
K & =\frac{\bar{\alpha}}{\delta} \frac{\bar{g}}{1-\bar{g}} C .
\end{aligned}
$$




\section{A.3 The log-linearized model}

We log-linearize the model around a deterministic zero-inflation steady state. Variables without a time subscript denote steady-state values and variables in lowercase denote percentage deviations from steady state $\left(z_{t}=\left(Z_{t}-Z\right) / Z\right)$, except for $g_{t}=\left(G_{t}-G\right) / Y$ and $g_{t}^{i}=\left(G_{t}^{i}-G^{i}\right) / Y$. Defining $r_{\beta, t}=-\ln \left(\beta_{t}\right), \bar{g}=G / Y$ and $\bar{\alpha}=G^{i} / G$, the log-linearized model is given by

$$
\begin{aligned}
y_{t} & =(1-\bar{g}) c_{t}+g_{t} \\
n_{t} & =\frac{F}{F_{N} N} y_{t}-\frac{F_{K} K}{F_{N} N} k_{t} \\
c_{t} & =E_{t} c_{t+1}+\frac{U_{C}}{U_{C C} C}\left(i_{t}-E_{t} \pi_{t+1}-r_{\beta, t}\right)-\frac{U_{C N} N}{U_{C C} C}\left(n_{t}-E_{t} n_{t+1}\right), \\
w_{t} & =\left(\frac{U_{C N} C}{U_{N}}-\frac{U_{C C} C}{U_{C}}\right) c_{t}+\left(\frac{U_{N N} N}{U_{N}}-\frac{U_{C N} N}{U_{C}}\right) n_{t}, \\
\pi_{t} & =\beta E_{t} \pi_{t+1}+\kappa\left(w_{t}-\frac{F_{N N} N}{F_{N}} n_{t}-\frac{F_{N K} K}{F_{N}} k_{t}\right) \\
k_{t} & =(1-\delta) k_{t-1}+\tilde{\delta} g_{t-T}, \\
i_{t} & =\max \left(0 ; r_{\beta, t}+\phi_{\pi} \pi_{t}\right)
\end{aligned}
$$

where

$$
\begin{aligned}
\kappa & =\frac{(1-\phi)(1-\beta \phi)}{\phi} \frac{-\frac{F_{N N} N}{F_{N}}}{-\frac{F_{N N} N}{F_{N}}+\theta\left(1+\frac{F_{N N} N}{F_{N}}\right)}>0, \\
\tilde{\delta} & =\frac{\alpha \delta}{\bar{\alpha} \bar{g}} \geq 0,
\end{aligned}
$$

and where we have used the fact that $g_{t}^{i}=\alpha g_{t}$.

\section{A.4 Functional forms and the implied composite parameters}

We consider the following production and utility functions:

$$
\begin{aligned}
U\left(C_{t}, N_{t}\right) & =\frac{\left(C_{t}^{\gamma}\left(1-N_{t}\right)^{1-\gamma}\right)^{1-\sigma}-1}{1-\sigma} & & \text { if } \sigma \neq 1 \\
& =\gamma \ln C_{t}+(1-\gamma) \ln \left(1-N_{t}\right) & & \text { if } \sigma=1
\end{aligned}
$$

and

$$
F\left(N_{t}, K_{t}\right)=N_{t}^{a} K_{t}^{b}
$$


These specifications imply the following first and second derivatives:

$$
\begin{aligned}
F_{N} & =a \frac{F(N, K)}{N}, \quad F_{K}=b \frac{F(N, K)}{K}, \\
U_{C} & =\gamma C^{\gamma(1-\sigma)-1}(1-N)^{(1-\gamma)(1-\sigma)}, \\
U_{C C} & =-(1+\gamma(\sigma-1)) \frac{U_{C}}{C}, \\
U_{C N} & =(1-\gamma)(\sigma-1) \frac{U_{C}}{1-N}, \\
U_{N} & =-\left[(1-\gamma) C^{\gamma(1-\sigma)}(1-N)^{(1-\gamma)(1-\sigma)-1}\right], \\
U_{N N} & =-\left[(1+(1-\gamma)(\sigma-1))(1-\gamma) C^{\gamma(1-\sigma)}(1-N)^{(1-\gamma)(1-\sigma)-2}\right] .
\end{aligned}
$$

The steady-state values for $C, N$, and $K$ are implicitly given by

$$
\begin{aligned}
C & =(1-\bar{g}) N^{a} K^{b}, \\
\frac{\theta-1}{(1-\tau) \theta} \frac{a}{1-\bar{g}} & =\frac{1-\gamma}{\gamma} \frac{N}{1-N}, \\
K & =\frac{\bar{\alpha}}{\delta} \frac{\bar{g}}{1-\bar{g}} C .
\end{aligned}
$$

The composite parameters $\Phi_{r}, \Phi_{g}, \Phi_{k}, \Theta_{g}, \Theta_{k}$, and $\Theta_{c}$, are given by

$$
\begin{aligned}
\Phi_{r} & =\frac{1}{1-\gamma(1-\sigma)+(1-\gamma)(1-\sigma) \frac{N}{1-N} \frac{1-g}{a}}=1, \\
\Phi_{g} & =\frac{1}{a}(1-\gamma)(\sigma-1) \frac{N}{1-N} \Phi_{r}=\frac{\gamma(\sigma-1)}{1-\bar{g}}, \\
\Phi_{k} & =b \Phi_{g}, \\
\Theta_{g} & =-\frac{\kappa}{a}\left((1-\gamma)(\sigma-1) \frac{N}{1-N}+a-1\right) \\
& +\frac{\kappa}{a} \frac{(1+(1-\gamma)(\sigma-1))(1-\gamma) C^{\gamma(1-\sigma)}(1-N)^{(1-\gamma)(1-\sigma)-1} \frac{N}{1-N}}{(1-\gamma) C^{\gamma(1-\sigma)}(1-N)^{(1-\gamma)(1-\sigma)-1}} \\
& =\frac{\kappa}{1-\bar{g}} \frac{\gamma}{1-\gamma}, \\
\Theta_{k} & =b\left(\kappa+\Theta_{g}\right), \\
\Theta_{c} & =\kappa+(1-\bar{g}) \Theta_{g}=\frac{\kappa}{1-\gamma} .
\end{aligned}
$$

\section{A.5 Analytical solution of the model with time to build $(T \geq 1)$}

In this subsection, we explain how we solve the model with time to build both in normal times and when the ZLB binds. In both cases, we use the method of undetermined coefficients. 


\section{A.5.1 Normal times}

Under the assumption that $\phi_{\pi}>1$, the unique linear rational expectation solution is given by

$$
\begin{aligned}
c_{t} & =\vartheta_{k} k_{t-1}+\sum_{\tau=0}^{T} \vartheta_{g}^{\tau} g_{t-\tau}, \\
\pi_{t} & =\zeta_{k} k_{t-1}+\sum_{\tau=0}^{T} \zeta_{g}^{\tau} g_{t-\tau} .
\end{aligned}
$$

Substituting these two expressions into equations (17)-(20) (with $i_{t}=r_{\beta}+\phi_{\pi} \pi_{t}$ ).and equating the relevant coefficients, we obtain

$$
\begin{aligned}
\vartheta_{k} & =(1-\delta) \frac{\kappa\left(\phi_{\pi}-(1-\delta)\right) \Phi_{r} \Theta_{k}-\delta(1-\beta(1-\delta)) \Phi_{k}}{\delta(1-\beta(1-\delta))+\kappa\left(\phi_{\pi}-(1-\delta)\right) \Phi_{r} \Theta_{c}} \\
\zeta_{k} & =-(1-\delta) \frac{\kappa \delta\left(\Theta_{c} \Phi_{k}+\Theta_{k}\right)}{\delta(1-\beta(1-\delta))+\kappa\left(\phi_{\pi}-(1-\delta)\right) \Phi_{r} \Theta_{c}}
\end{aligned}
$$

and

$$
\begin{aligned}
\left(\begin{array}{c}
\vartheta_{g}^{0} \\
\zeta_{g}^{0}
\end{array}\right) & =\tilde{\delta} \Lambda \mathbf{A}\left(\begin{array}{c}
\vartheta_{g}^{1} \\
\zeta_{g}^{1}
\end{array}\right)+\left(\begin{array}{c}
(1-\rho \beta)\left[\tilde{\delta} \Phi_{k}+(1-\rho) \Phi_{g}\right]-\kappa\left(\phi_{\pi}-\rho\right) \Phi_{r} \Theta_{g} \\
\kappa(1-\rho) \Theta_{g}+\kappa\left[\tilde{\delta} \Phi_{k}+(1-\rho) \Phi_{g}\right] \Theta_{c}
\end{array}\right), \\
\left(\begin{array}{c}
\vartheta_{g}^{\tau} \\
\zeta_{g}^{\tau}
\end{array}\right) & =\varpi \mathbf{B}\left(\begin{array}{c}
\vartheta_{g}^{\tau+1} \\
\zeta_{g}^{\tau+1}
\end{array}\right), \quad \tau=1, \ldots, T-2 ; \quad \text { for } T>2, \\
\left(\begin{array}{c}
\vartheta_{g}^{T-1} \\
\zeta_{g}^{T-1}
\end{array}\right) & =\varpi \mathbf{B}\left(\begin{array}{c}
\vartheta_{g}^{T} \\
\zeta_{g}^{T}
\end{array}\right)+\tilde{\delta} \varpi\left(\begin{array}{c}
\Phi_{k} \\
\kappa \Theta_{c} \Phi_{k}
\end{array}\right), \quad \text { for } T>1, \\
\left(\begin{array}{c}
\vartheta_{g}^{T} \\
\zeta_{g}^{T}
\end{array}\right) & =\tilde{\delta} \varpi \mathbf{B}\left(\begin{array}{c}
\vartheta_{k} \\
\zeta_{k}
\end{array}\right)+\tilde{\delta} \varpi\left(\begin{array}{c}
\kappa \phi_{\pi} \Phi_{r} \Theta_{k}-\delta \Phi_{k} \\
\kappa\left(\Theta_{k}+\delta \Theta_{c} \Phi_{k}\right)
\end{array}\right), \quad \text { for } T \geq 1,
\end{aligned}
$$

where

$$
\Lambda=\left((1-\rho)(1-\beta \rho)+\kappa\left(\phi_{\pi}-\rho\right) \Phi_{r} \Theta_{c}\right)^{-1}, \quad \varpi=\left(1+\kappa \phi_{\pi} \Phi_{r} \Theta_{c}\right)^{-1},
$$

and

$$
\mathbf{A}=\left(\begin{array}{cc}
1-\beta \rho & \left(1-\beta \phi_{\pi}\right) \Phi_{r} \\
\kappa \Theta_{c} & \kappa \Phi_{r} \Theta_{c}+\beta(1-\rho)
\end{array}\right), \quad \mathbf{B}=\left(\begin{array}{cc}
1 & \left(1-\beta \phi_{\pi}\right) \Phi_{r} \\
\kappa \Theta_{c} & \kappa \Phi_{r} \Theta_{c}+\beta
\end{array}\right)
$$

In practice, for any arbitrary $T, \vartheta_{g}^{\tau}$, and $\zeta_{g}^{\tau}(\tau=0, \ldots, T)$ are computed backward recursively: Start by computing $\vartheta_{g}^{T}$ and $\zeta_{g}^{T}$, which are only functions of the deep parameters. Once $\vartheta_{g}^{T}$ and $\zeta_{g}^{T}$ are known, compute $\vartheta_{g}^{T-1}$ and $\zeta_{g}^{T-1}$, and so on up to $\vartheta_{g}^{0}$ and $\zeta_{g}^{0}$. 


\section{A.5.2 Liquidity trap}

When the ZLB binds $\left(i_{t}=0\right)$, equations (17)-(20) imply

$$
\begin{aligned}
c_{t}^{l} & =E_{t} c_{t+1}-\Phi_{r}\left(-E_{t} \pi_{t+1}-i_{\beta, t}\right)+\Phi_{g}\left(g_{t}^{l}-E_{t} g_{t+1}\right)-\Phi_{k}\left(\delta k_{t}-\tilde{\delta} E_{t} g_{t-(T-1)}\right), \\
\pi_{t}^{l} & =\beta E_{t} \pi_{t+1}+\Theta_{c} c_{t}^{l}+\Theta_{g} g_{t}^{l}-\Theta_{k} k_{t} .
\end{aligned}
$$

The unique linear rational expectation solution is given by

$$
\begin{aligned}
& c_{t}^{l}=\vartheta_{i}^{l} r_{\beta}^{l}+\vartheta_{k}^{l} k_{t-1}+\sum_{\tau=0}^{T} \vartheta_{g}^{l, \tau} g_{t-\tau}, \\
& \pi_{t}^{l}=\zeta_{i}^{l} r_{\beta}^{l}+\zeta_{k}^{l} k_{t-1}+\sum_{\tau=0}^{T} \zeta_{g}^{l, \tau} g_{t-\tau} .
\end{aligned}
$$

Unlike the simple case discussed in Section 3.2, whenever the ZLB ceases to bind, the economy does not immediately jump to the steady state, as the stock of public capital continues to adjust. Thus, the expected value of a given variable in $t+1$ is an average of its possible values in $t+1$ inside and outside the liquidity trap, weighted by the respective probabilities of being in these two states. Using the equilibrium paths of consumption and inflation inside and outside the ZLB state, we obtain

$$
\begin{aligned}
& E_{t} c_{t+1}=p\left(\vartheta_{i}^{l} r_{\beta}^{l}+\vartheta_{k}^{l} k_{t-1}+\vartheta_{g}^{l, 0} g_{t}+\sum_{\tau=1}^{T} \vartheta_{g}^{l, \tau} g_{t+1-\tau}\right)+(1-p)\left(\vartheta_{k} k_{t-1}+\sum_{\tau=1}^{T} \vartheta_{g}^{\tau} g_{t+1-\tau}\right), \\
& E_{t} \pi_{t+1}=p\left(\zeta_{i}^{l} r_{\beta}^{l}+\zeta_{k}^{l} k_{t-1}+\zeta_{g}^{l, 0} g_{t}+\sum_{\tau=1}^{T} \zeta_{g}^{l, \tau} g_{t+1-\tau}\right)+(1-p)\left(\zeta_{k} k_{t-1}+\sum_{\tau=1}^{T} \zeta_{g}^{\tau} g_{t+1-\tau}\right),
\end{aligned}
$$

where we have used the fact that

$$
\begin{aligned}
g_{t+1} & =g_{t} \text { if the ZLB is still binding in } t+1, \\
& =0 \text { otherwise. }
\end{aligned}
$$

Equating the relevant coefficients yields

$$
\begin{aligned}
\vartheta_{i}^{l} & =\frac{(1-\beta p) \Phi_{r}}{(1-p)(1-\beta p)-p \kappa \Phi_{r} \Theta_{c}} \\
\zeta_{i}^{l} & =\frac{\Theta_{c} \Phi_{r}}{(1-p)(1-\beta p)-p \kappa \Phi_{r} \Theta_{c}}
\end{aligned}
$$




$$
\begin{aligned}
\vartheta_{k}^{l} & =\frac{(1-p)(1-\delta)\left[(1-p \beta(1-\delta)) \vartheta_{k}+\Phi_{r} \zeta_{k}\right]-p \kappa(1-\delta)^{2} \Phi_{r} \Theta_{k}-(1-\delta)(1-p \beta(1-\delta)) \delta \Phi_{k}}{(1-p(1-\delta))(1-\beta p(1-\delta))-p \kappa(1-\delta) \Phi_{r} \Theta_{c}}, \\
\zeta_{k}^{l} & =\frac{(1-p)(1-\delta)\left\{\kappa \Theta_{c} \vartheta_{k}+\left[\beta(1-p(1-\delta))+\kappa \Theta_{c} \Phi_{r}\right] \zeta_{k}\right\}-\kappa(1-\delta)\left[(1-p \beta(1-\delta)) \Theta_{k}+\delta \Theta_{c} \Phi_{k}\right]}{(1-p(1-\delta))(1-\beta p(1-\delta))-p \kappa(1-\delta) \Phi_{r} \Theta_{c}}
\end{aligned}
$$

and

$$
\begin{aligned}
\left(\begin{array}{c}
\vartheta_{g}^{l, 0} \\
\zeta_{g}^{l, 0}
\end{array}\right) & =\tilde{\delta} \Lambda^{l} \mathbf{A}^{l}\left[p\left(\begin{array}{c}
\vartheta_{g}^{l, 1} \\
\zeta_{g}^{l, 1}
\end{array}\right)+(1-p)\left(\begin{array}{c}
\vartheta_{g}^{1} \\
\zeta_{g}^{1}
\end{array}\right)\right]+\Lambda^{l}\left(\begin{array}{c}
(1-p \beta)(1-p) \Phi_{g}+p \kappa \Phi_{r} \Theta_{g} \\
\kappa(1-p)\left(\Theta_{g}+\Phi_{g} \Theta_{c}\right)
\end{array}\right), \\
\left(\begin{array}{c}
\vartheta_{g}^{l, \tau} \\
\zeta_{g}^{l, \tau}
\end{array}\right) & =p \mathbf{B}^{l}\left(\begin{array}{c}
\vartheta_{g}^{l, \tau+1} \\
\zeta_{g}^{l, \tau+1}
\end{array}\right)+(1-p) \mathbf{B}^{l}\left(\begin{array}{c}
\vartheta_{g}^{\tau+1} \\
\zeta_{g}^{\tau+1}
\end{array}\right), \quad \begin{array}{c}
\tau \\
\tau+\ldots, T-2, \quad \text { for } T>2,
\end{array} \\
\left(\begin{array}{c}
\vartheta_{g}^{l, T-1} \\
\zeta_{g}^{l, T-1}
\end{array}\right) & =p \mathbf{B}^{l}\left(\begin{array}{c}
\vartheta_{g}^{l, T} \\
\zeta_{g}^{l, T}
\end{array}\right)+(1-p) \mathbf{B}^{l}\left(\begin{array}{c}
\vartheta_{g}^{T} \\
\zeta_{g}^{T}
\end{array}\right)+\left(\begin{array}{c}
\tilde{\delta} \Phi_{k} \\
\kappa \tilde{\delta} \Theta_{c} \Phi_{k}
\end{array}\right), \quad \text { for } T>1, \\
\left(\begin{array}{c}
\vartheta_{g}^{T} \\
\zeta_{g}^{T}
\end{array}\right) & =p \tilde{\delta} \mathbf{B}^{l}\left(\begin{array}{c}
\vartheta_{k}^{l} \\
\zeta_{k}^{l}
\end{array}\right)+(1-p) \tilde{\delta} \mathbf{B}^{l}\left(\begin{array}{c}
\vartheta_{k} \\
\zeta_{k}
\end{array}\right)-\left(\begin{array}{c}
\delta \tilde{\delta} \Phi_{k} \\
\kappa \tilde{\delta}\left(\delta \Theta_{c} \Phi_{k}+\Theta_{k}\right)
\end{array}\right), \quad \text { for } T \geq 1,
\end{aligned}
$$

where

$$
\Lambda^{l}=\left((1-p)(1-\beta p)-p \kappa \Phi_{r} \Theta_{c}\right)^{-1},
$$

and

$$
\mathbf{A}^{l}=\left(\begin{array}{cc}
1-p \beta & \Phi_{r} \\
\kappa \Theta_{c} & \kappa \Phi_{r} \Theta_{c}+\beta(1-p)
\end{array}\right), \quad \mathbf{B}^{l}=\left(\begin{array}{cc}
1 & \Phi_{r} \\
\kappa \Theta_{c} & \kappa \Phi_{r} \Theta_{c}+\beta
\end{array}\right) .
$$

Again, the coefficients $\vartheta_{g}^{l, \tau}$ and $\zeta_{g}^{l, \tau}(\tau=0, \ldots, T)$ are computed recursively starting from period $T$.

\section{A.6 Figures}




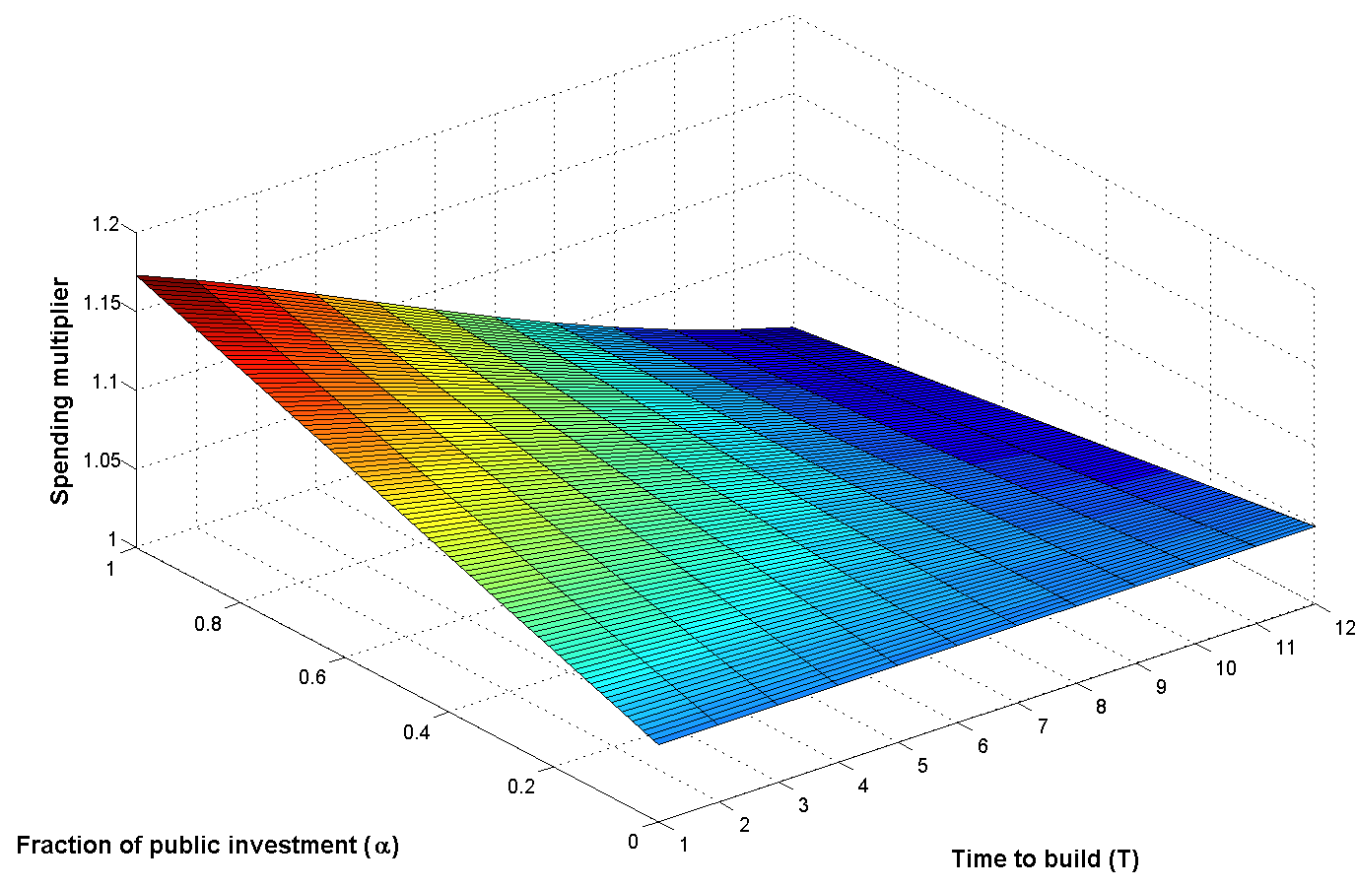

Figure 7: Spending multiplier as a function of the share of public investment and time-to-build delay in normal times, non-separable preferences $(\sigma=2)$. 


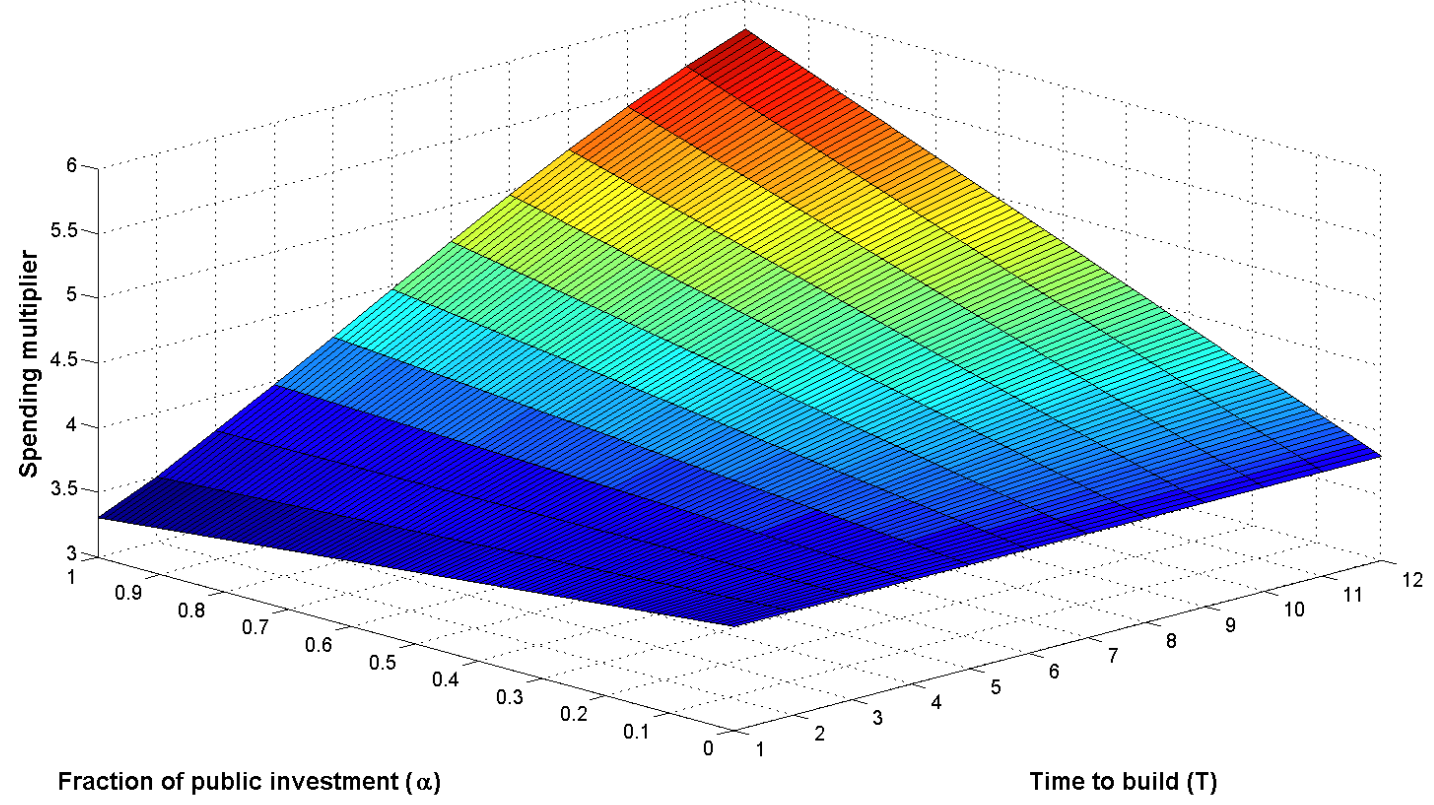

Figure 8: Spending multiplier as a function of the share of public investment and time-to-build delay in a liquidity trap, non-separable preferences $(\sigma=2)$. 